\title{
Gelcast Zirconia Ceramics With High Strength and Simultaneously High Translucency for Dental Applications
}

Jaroslav Kastyl ( $\sim$ Jaroslav.Kastyl@ceitec.vutbr.cz )

Brno University of Technology https://orcid.org/0000-0001-8145-604X

Zdenek Chlup

Institute of Physics of Materials, Czech Academy of Sciences

Vaclav Pouchly

Brno University of Technology

Lu Song

Tsinghua University

Erik Scasnovic

Brno University of Technology

Martin Trunec

Brno University of Technology

\section{Research Article}

Keywords: zirconia, nanoparticles, gelcasting, biaxial strength, translucency, dental restoration

Posted Date: July 27th, 2021

DOI: https://doi.org/10.21203/rs.3.rs-736845/v1

License: () (1) This work is licensed under a Creative Commons Attribution 4.0 International License.

Read Full License 
Gelcast zirconia ceramics with high strength and simultaneously high translucency for dental applications

Jaroslav Kastyl $^{1 *}$, Zdenek Chlup ${ }^{2}$, Vaclav Pouchly ${ }^{1}$, Lu Song ${ }^{3}$, Erik Scasnovic ${ }^{1}$, Martin Trunec ${ }^{1,4}$

${ }^{1}$ CEITEC BUT, Brno University of Technology, Purkynova 123, 61200 Brno, the Czech Republic

${ }^{2}$ CEITEC IPM, Institute of Physics of Materials, Czech Academy of Sciences, Zizkova 22, 61600 Brno, the Czech Republic

${ }^{3}$ State Key Laboratory of New Ceramics and Fine Processing, School of Materials Science and Engineering, Tsinghua University, Beijing 100084, China

${ }^{4}$ Department of Materials Science and Engineering, Brno University of Technology, Technicka 2, 61669 Brno, the Czech Republic

* Corresponding author:

Central European Institute of Technology, Brno University of Technology

Purkynova 123, 61200 Brno, the Czech Republic

Tel.: +420 541149710

e-mail: Jaroslav.Kastyl@Ceitec.Vutbr.cz 


\begin{abstract}
Translucent zirconia represents a favourite material for monolithic ceramic dental restorations. However, materials approaches employed so far to improve the translucency of zirconia ceramics are accompanied by a significant decline in strength. Thus, we aimed to develop dental $3 \mathrm{Y}$-TZP ceramics that can provide excellent strength and, simultaneously, enhanced translucency. In this investigation, machinable tetragonal zirconia ceramics based on fine mesostructured zirconia particles stabilized with 3 mol\% of yttria and prepared by the gelcasting processing method were developed. Properties of sintered samples were characterised, namely: shrinkage, density, structure, surface roughness, hardness, biaxial strength, and total forward transmittance. Zirconia ceramics with an average biaxial strength of $1184 \mathrm{MPa}$ and a total forward transmittance of $46.7 \%$ for a $0.5 \mathrm{~mm}$ thick sample at a wavelength of $600 \mathrm{~nm}$ were obtained. These ceramics exhibited homogeneous structure with grains sizes up to $620 \mathrm{~nm}$ and purely tetragonal phase composition. The developed ceramics provided a favourable combination of high translucency comparable even with the mixed cubic/tetragonal structure of a common 4Y-TZP, and very high strength that is achievable only in the pure tetragonal $3 \mathrm{Y}-\mathrm{TZP}$.
\end{abstract}

\title{
Keywords
}

zirconia; nanoparticles; gelcasting; biaxial strength; translucency; dental restoration

\section{Introduction}

The development of a manufacturing technology based on CAD/CAM milling of pre-sintered blanks in the shape of discs or blocks has enabled the production of all-ceramic full-contour restorations $[1,2]$. Among the ceramics used for CAD/CAM milling in dentistry, zirconia ceramics attract ever growing attention of dental professionals as well as patients. Tetragonal 
zirconia polycrystals stabilised with yttria (Y-TZP) are favourable because of their biocompatibility, chemical stability, high fracture toughness, and excellent flexural strength. Unfortunately, the conventional tetragonal zirconia ceramics stabilised with 3 mol\% of yttria (3Y-TZP) exhibit an opaque appearance, i.e. low optical translucency. As low translucency negatively affects the aesthetics of the restoration, the conventional zirconia ceramics have had to be veneered with more translucent glass-based materials known as veneering porcelain $[3,4]$. However, chipping and fracturing of the veneering porcelains have often been registered [5-8] and this shortcoming of veneered zirconia materials resulted in the introduction of and ongoing extensive investigation into monolithic Y-TZP restorations with improved translucency [9-13]. A measure of translucency is the total forward transmittance of light, i.e. the fraction of incident light intensity transmitted through the material in the forward direction [14]. The main reasons for limited translucency of tetragonal zirconia include high light reflection at the body surfaces, light absorption in the material, scattering at pores or inclusions, and scattering at grain boundaries of birefringent tetragonal zirconia $[15,16]$. Three methods for improving translucency have been reported [17-19]. The principle of all these methods consists in reducing the backscattering in the ceramics because other factors are difficult to control. The first method for reducing backscattering is based on the elimination of inclusions whose refractive index is different from the refractive index of the ceramic matrix. Not only impurities but also residual pores can be regarded as inclusions with a high scattering effect. Primarily, inclusions of a size similar to the wavelength of visible light significantly reduce translucency $[14,16]$. Thus, alumina, which is often used as a dopant for tetragonal zirconia ceramics $[13,20]$, must be eliminated from translucent zirconia. It was shown that an addition of 0.3 mol\% of alumina to $3 \mathrm{Y}-\mathrm{TZP}$ decreased the translucency of a $1 \mathrm{~mm}$ thick sample from $\sim 38 \%$ to $\sim 30 \%$ [20]. However, the absence of alumina makes sintering more difficult, decreases strength, and increases the propensity for low-temperature 
degradation [21-23]. The second method uses grain size adjustment in sintered tetragonal zirconia ceramics. Theoretical models predict that scattering at grain boundaries diminishes as the grain size becomes much lower than the wavelength of transmitted light $[16,24,25]$. On the other hand, in a very coarse-grained structure, the transmitting light interacts with fewer grain boundaries. Unfortunately, the optimum grain size for the best mechanical properties of common tetragonal 3Y-TZP usually lies between 300 and $600 \mathrm{~nm}$, i.e. at grain sizes comparable with the wavelengths of visible light [26]. At smaller grain sizes, the transformation toughening effect decreases due to an "overstabilisation" of the tetragonal grains $[26,27]$. At larger grain sizes, the spontaneous transformation of tetragonal $\left(\mathrm{t}-\mathrm{ZrO}_{2}\right)$ to monoclinic $\left(\mathrm{m}-\mathrm{ZrO}_{2}\right)$ phase occurs $[26,28,29]$. In both cases, the mechanical properties are dramatically reduced. The third method increases translucency by decreasing the birefringence of zirconia ceramics. Zirconia ceramics stabilised with 4-5 mol\% of yttria (4YTZP or 5Y-TZP) result in materials with a biphasic tetragonal/cubic structure with a varying content of the cubic phase of up to $50 \%$ [30-32]. The presence of the cubic phase $\left(\mathrm{c}-\mathrm{ZrO}_{2}\right)$ in the tetragonal structure reduces the light scattering at grain boundaries and the tetragonal/cubic zirconia ceramics thus exhibit higher translucency compared with pure tetragonal zirconia ceramics. On the other hand, the $\mathrm{c}-\mathrm{ZrO}_{2}$ cannot undergo the transformation toughening effect, and the strength of tetragonal/cubic zirconia ceramics is lowered to $50-75 \%$ of the conventional high-strength tetragonal 3Y-TZP ceramics that can reach up to $1200 \mathrm{MPa}$ in the 3-point bending [13, 33-35]. Recently, gradient multilayer pre-sintered discs have been developed with yttria content changing from $5 \mathrm{~mol} \%$ at the top to $3 \mathrm{~mol} \%$ at the bottom of the disc [36]. Although this disc design brings a better aesthetics of dental restorations, it exhibits a gradient in strength as well. The reliability of such structures is still questionable and need to be investigated in detail [37]. It follows from this short overview that an improvement of zirconia ceramics translucency always results in their strength deterioration. In applications of 
dental zirconia ceramics, dental professionals must always seek a compromise between translucency and strength. Other properties such as fracture toughness, hardness, abrasiveness, colouring, etc. can also be affected by the translucency improvement. Thus, an investigation into improving translucency without affecting other properties of zirconia ceramics, mainly strength, is still a challenging topic. In the case of multi-unit monolithic restorations with their demand for very high strength and reliability, the only way to increase translucency is the development of a pore- and impurity-free optimized tetragonal microstructure. Gelcasting is a colloidal processing method that can provide ceramic bodies with a more homogeneous and denser microstructure than can be obtained by uniaxial pressing or cold isostatic pressing, the common methods for the preparation of dental zirconia blanks [38]. The benefits of the gelcasting method arise from a regular and tight packing of well-dispersed particles $[39,40]$. However, the preparation of large machinable zirconia discs from nano-sized powders by the gelcasting method is a tricky process that needs to be investigated and carefully developed. Thus, in this investigation, we aimed to develop dental 3Y-TZP ceramics based on the gelcasting of zirconia nanoparticles that can provide excellent strength and, simultaneously, enhanced translucency.

\section{Experimental}

\subsection{Preparation of ceramic blanks}

Zirconia powder SZ (SZ-DT-SE3, JiangXi Size Materials, China) stabilised with 3 mol\% of $\mathrm{Y}_{2} \mathrm{O}_{3}$ was used to prepare machinable zirconia blanks by the gelcasting method [41]. Zirconia powder was dispersed in a premix solution of monomers, using a commercial Dolapix CE 64 dispersant (Zschimmer \& Schwarz, Germany). The premix solution was prepared by dissolving monomers in deionised water. Methacrylamide (109606, Sigma-Aldrich Chemie, Germany) and N, N '-methylene bisacrylamide (146072, Sigma-Aldrich Chemie, Germany) 
were used as the linear monomer and cross-linker, respectively. The monomer ratio of the linear to the cross-linking monomer was 4:1. Polyethylene glycol 400 (8.07485, SigmaAldrich Chemie, Germany) as a drying additive (PEG) was used to improve the drying process of the gelled body. The content of individual components in suspension is listed in Table 1. The applied composition of the suspension and particularly the content of PEG were essential for defect-less production of large zirconia blanks and were based on an extensive investigation that goes beyond the scope of this article.

Table 1 Composition of the zirconia suspension.

\begin{tabular}{|c|c|c|c|c|}
\hline Powder & Monomers & Dispersant & PEG & Water \\
\hline (wt\% / vol\%) & $(\mathrm{wt} \%)$ & $(w t \%)$ & $(w t \%)$ & $(\mathrm{wt} \%)$ \\
\hline $81.3 / 42.0$ & 1.8 & 0.5 & 1.6 & 14.8 \\
\hline
\end{tabular}

The ceramic suspension was ball-milled with $1 \mathrm{~mm}$ zirconia balls (YTZ, Nikkato-Tosoh, Japan) for $24 \mathrm{~h}$. After the ball milling, the suspension was degassed for 15 min under a pressure of $9 \cdot 10^{3} \mathrm{~Pa} .0 .175 \mathrm{wt} \%$ of ammonium persulfate (215589, Sigma-Aldrich Chemie, Germany) with respect to pure monomers was added as a $2.5 \%$ water solution to initiate the polymerisation of dissolved monomers at room temperature $[42,43]$. After the addition of initiator, the ceramic suspension was cast into non-porous moulds and gelled under a nitrogen atmosphere to accomplish complete polymerisation during $2 \mathrm{~h}$. Bodies in the shape of discs (diameter of $30 \mathrm{~mm}$ and thickness of $6 \mathrm{~mm}$ ), blocks (diameter of 23-27 $\mathrm{mm}$ and height of 24$41 \mathrm{~mm}$ ) and standard machinable discs (diameter of $100 \mathrm{~mm}$ and thickness of $15 \mathrm{~mm}$ ) were cast. The zirconia bodies were removed from the moulds after gelation and dried in a climate box at $20{ }^{\circ} \mathrm{C}$. The relative humidity in the climate box was decreased gradually from $98 \%$ to $60 \%$ in $168 \mathrm{~h}$, followed by final drying under laboratory conditions. Zirconia bodies prepared 
by gelcasting were pre-sintered at $1000{ }^{\circ} \mathrm{C}$ for $1 \mathrm{~h}$ with a heating rate of $50{ }^{\circ} \mathrm{C} \mathrm{h}^{-1}$ up to 500 ${ }^{\circ} \mathrm{C}$, followed by a heating rate of $120^{\circ} \mathrm{C} \mathrm{h}^{-1}$ up to the pre-sintering temperature. In addition, the heating rate was lowered to $25^{\circ} \mathrm{C} \mathrm{h}^{-1}$ in the temperature range of $100-400{ }^{\circ} \mathrm{C}$ in order to safely remove the drying additive (PEG) and other organic species from the particle compacts.

\subsection{CNC milling and final sintering}

A diamond-coated toroid mill (flat-end mill D-EPDR-2020-20-02 Epoch21, MMC Hitachi Tool Engineering Europe, Germany) with a corner radius of $0.2 \mathrm{~mm}$ and an end diameter of $2 \mathrm{~mm}$ was used for milling specimens for strength measurements from the pre-sintered ceramic discs (dia. $30 \mathrm{~mm}$, thickness $6 \mathrm{~mm}$ ). The milling parameters were as follows: depth of cut $a_{p}=0.5 \mathrm{~mm}$ and width of cut $a_{e}=0.8 \mathrm{~mm}$ for initial roughening, and $a_{p}=0.1 \mathrm{~mm}$ and $a_{e}=0.8 \mathrm{~mm}$ for finishing in the last step. Further details of milling can be found in our previous study [41]. The milled samples were sintered in an air atmosphere at a heating rate of $10{ }^{\circ} \mathrm{C} \min ^{-1}$ up to $800{ }^{\circ} \mathrm{C}$, followed by a heating rate of $5{ }^{\circ} \mathrm{C} \min ^{-1}$ up to the final sintering temperature. Sintering temperatures of 1350,1450 , and $1550{ }^{\circ} \mathrm{C}$ with a $2 \mathrm{~h}$ dwell time were applied.

\subsection{Evaluation methods}

The specific surface area of the zirconia powder was measured by nitrogen adsorption according to the multipoint BET method (Autosorb iQ, Quantachrome, USA). Particle size distribution in the ceramic suspension was determined using dynamic light scattering (Zetasizer Nano ZS, Malvern, UK). The bulk densities of pre-sintered and sintered samples were determined in distilled water by the Archimedes method following the EN 623-2 standard [44], always for at least three samples. The relative densities were calculated using a 
theoretical density (t.d.) of $6.1 \mathrm{~g} \mathrm{~cm}^{-3}$ for $\mathrm{t}-\mathrm{ZrO}_{2}$ [45]. The densification curve was calculated from high-temperature dilatometer measurements (Linseis L75 Platinum edition, Linseis, Germany) by a procedure described in [46]. The presence of surface defects (such as pores, cracks or delamination) in sintered samples was determined using the penetration test described in [47]. The microstructure of the powder and sintered samples was analysed using scanning electron microscopy (SEM) (Verios 4601, FEI, USA) and transmission electron microscopy (TEM) (Titan Themis 60-300, FEI, USA). The average grain size was determined by the intercept method on SEM micrographs of polished and thermally etched surfaces, according to ASTM E1382 [48]. At least 300 intercept lengths were used for a histogram construction and average grain size calculation. The average linear intercept grain size was multiplied by a factor of 1.56 to yield the true grain size [49]. X-ray diffraction (XRD) measurements on sintered samples with untreated surfaces were carried out by the Rigaku SmartLab 3 kW X-ray diffractometer (Rigaku, Tokyo, Japan). The diffraction patterns were measured from $10^{\circ}$ to $90^{\circ}(2 \theta)$ with the $\mathrm{Cu} \mathrm{K \alpha}$ radiation (current $30 \mathrm{~mA}$, voltage $40 \mathrm{kV}$ ). Phase analyses were performed using the full pattern with PDXL-2 software. The Rietveld method was employed to quantify the phase composition. The crystallographic data were obtained from CIF (Crystallographic Information File) sheets selected from the ICSD (Inorganic Crystal Structure Database) and then used as standards in the analysis software mentioned above. The CIF files no. 80050, 66783, 53998 were selected for $\mathrm{m}-\mathrm{ZrO}_{2}, \mathrm{t}-\mathrm{ZrO}_{2}$ and $\mathrm{c}-\mathrm{ZrO}_{2}$, respectively.

The biaxial flexural strength was determined using a universal testing machine (8862, Instron, USA) in the ball-on-3-balls configuration for sintered ceramic discs. The dimensions of sintered ceramic discs were about $23 \mathrm{~mm}$ in diameter and $3 \mathrm{~mm}$ in thickness. The supporting and loading steel balls had a diameter of $17.463 \mathrm{~mm}$ (giving a supporting circle diameter of 
approx. $20 \mathrm{~mm}$ ). Loading at a crosshead speed of $0.5 \mathrm{~mm} \mathrm{~min}^{-1}$ was used. The strength values were calculated from the maximum (fracture) force, disc thickness and the numerically calculated geometrical factor $f$ for the given geometry and the combination of materials. The factor $f$ was calculated and equalled to 2.05 for every group of specimens tested in our work. More details of the biaxial strength measurement can be found elsewhere [50]. At least 20 valid strength values for each experimental group were statistically analysed. The Weibull strength distribution parameters were calculated numerically, using the maximum likelihood method, with the $90 \%$ confidence intervals following the EN 843-5 standard [51]. The hardness of sintered samples was determined using an instrumented hardness testing system Zwick Z2.5, equipped with the ZHU02 instrumented hardness head (Zwick/Roell, Germany) on polished discs. Before the comparative hardness measurement, the dependence of hardness values on the applied load was determined to estimate the minimum load without the size effect. It was found that applied loads higher than 19.614 N (HV2) provided constant hardness values. Therefore, a load of $49.035 \mathrm{~N}$ (HV5) with a dwell time of $15 \mathrm{~s}$ was selected for comparing all sample groups. The total forward transmittance (TFT) of sintered and polished samples (polished with diamond paste as fine as $1 \mu \mathrm{m}$ ) with nominal thicknesses of $0.5 \mathrm{~mm}$ and $1.0 \mathrm{~mm}$ was measured with a spectrophotometer (Specord 250 Plus, Analytik Jena AG, Germany). The spectrophotometer was equipped with an integrating sphere with a spherical diameter of $75 \mathrm{~mm}$. Each sample was analysed five times in the wavelength range $300-800 \mathrm{~nm}$, and the mean transmittance was evaluated according to ASTM E1348 [52]. The surface roughness of milled samples was analysed after sintering with a DektakXT stylus profilometer (Bruker Corporation, USA) according to the EN ISO 4287 and EN ISO 4288 standards $[53,54]$. A profilometer tip radius of $2 \mu \mathrm{m}$ was used. The data obtained by the profilometer were processed by the Gwyddion software [55]. 


\section{Results and discussion}

\subsection{Preparation and sintering behaviour of zirconia blanks}

Images of the SZ zirconia powder used for the preparation of ceramic suspensions are shown in Fig. 1. Most of the primary particles were below $100 \mathrm{~nm}$ (Fig. 1a) and they were predominantly aggregated in bigger mesostructured particles of about $150-200 \mathrm{~nm}$ (as can be seen in the TEM image in Fig. 1b). These mesostructured particles consisted of individual crystals and exhibited mesoporous or dense structure [56]. This visual evaluation of the powder was supported by its high specific surface area of $11.8 \mathrm{~m}^{2} \mathrm{~g}^{-1}$, which corresponded to an average particle size of $83 \mathrm{~nm}$. Fig. 2 shows particle size distribution in the ceramic suspension after the powder dispersion by ball milling.

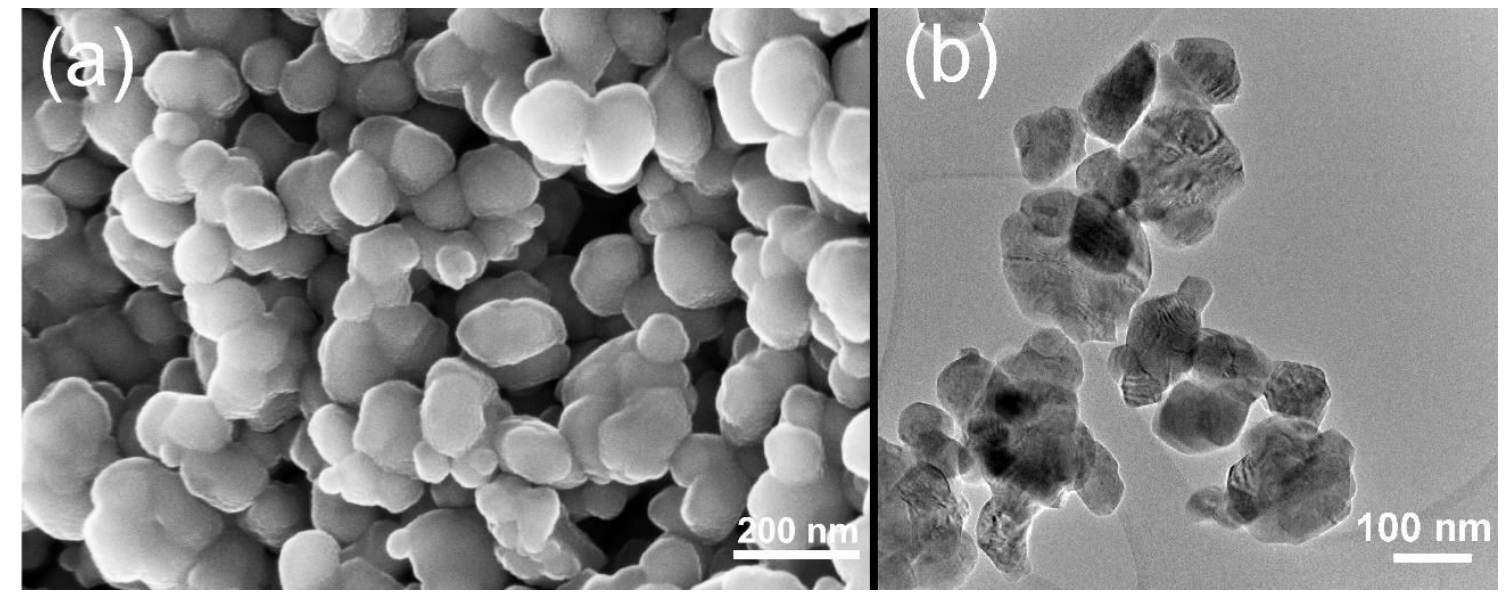

Fig. 1 Morphology of SZ-3Y zirconia powder shown in a) SEM and b) TEM imaging mode.

The particles in the SZ suspensions were finely dispersed and reached a relatively narrow particle size distribution in the range from 75 to $200 \mathrm{~nm}$ with a mode of $140 \mathrm{~nm}$. The particle size measurement confirmed that the powder was dispersed into the individual mesostructured particles observed in the TEM image. Pore size distributions in zirconia bodies pre-sintered to different temperatures are also presented in Fig. 2. 


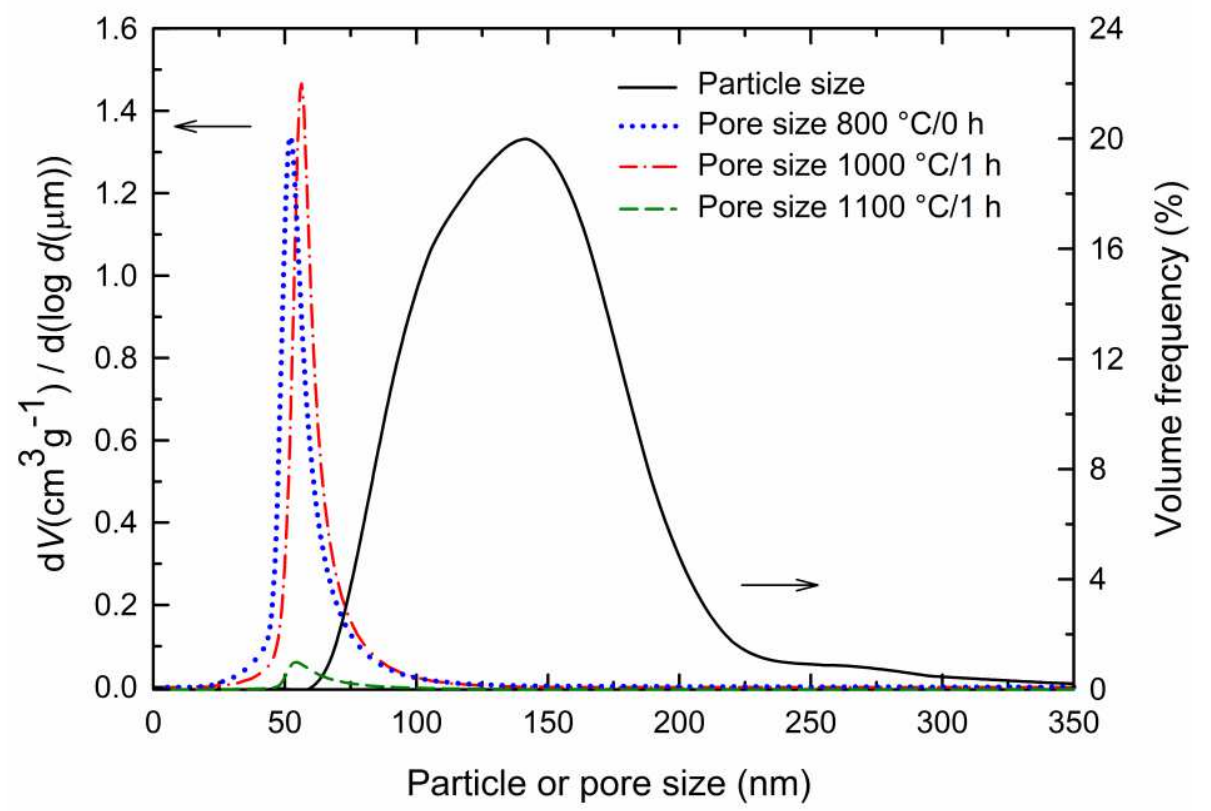

Fig. 2 Particle size distribution in zirconia suspensions after ball milling and pore size distribution in zirconia bodies pre-sintered to $800{ }^{\circ} \mathrm{C} / 0 \mathrm{~h}, 1000{ }^{\circ} \mathrm{C} / 1 \mathrm{~h}$, and $1100{ }^{\circ} \mathrm{C} / 1 \mathrm{~h}$.

It is shown that the pore size distribution in the particle compacts after binder removal with a minimum densification $\left(800^{\circ} \mathrm{C} / 0 \mathrm{~h}\right)$ was very narrow, with the most frequent pore size of 60 $\mathrm{nm}$, which was well below the size of the particles used. It follows from the comparison of particle and pore sizes that the particles in the gelcast bodies were homogeneously and regularly packed without any large interagglomerate pores. Moreover, the similar pore size distributions in bodies pre-sintered to higher temperatures $\left(1000^{\circ} \mathrm{C} / 1 \mathrm{~h}, 1100{ }^{\circ} \mathrm{C} / 1 \mathrm{~h}\right)$ demonstrated homogeneous sintering without preferential densification of denser particle domains. The preferential densification of denser domains is typical of inhomogeneously packed compacts prepared from agglomerated nanoparticles and is accompanied by pore opening in the first stage of sintering [57-60]. Fig. 3 shows the sintering behaviour of the zirconia sample pre-sintered at $1000^{\circ} \mathrm{C}$ for $1 \mathrm{~h}$. 


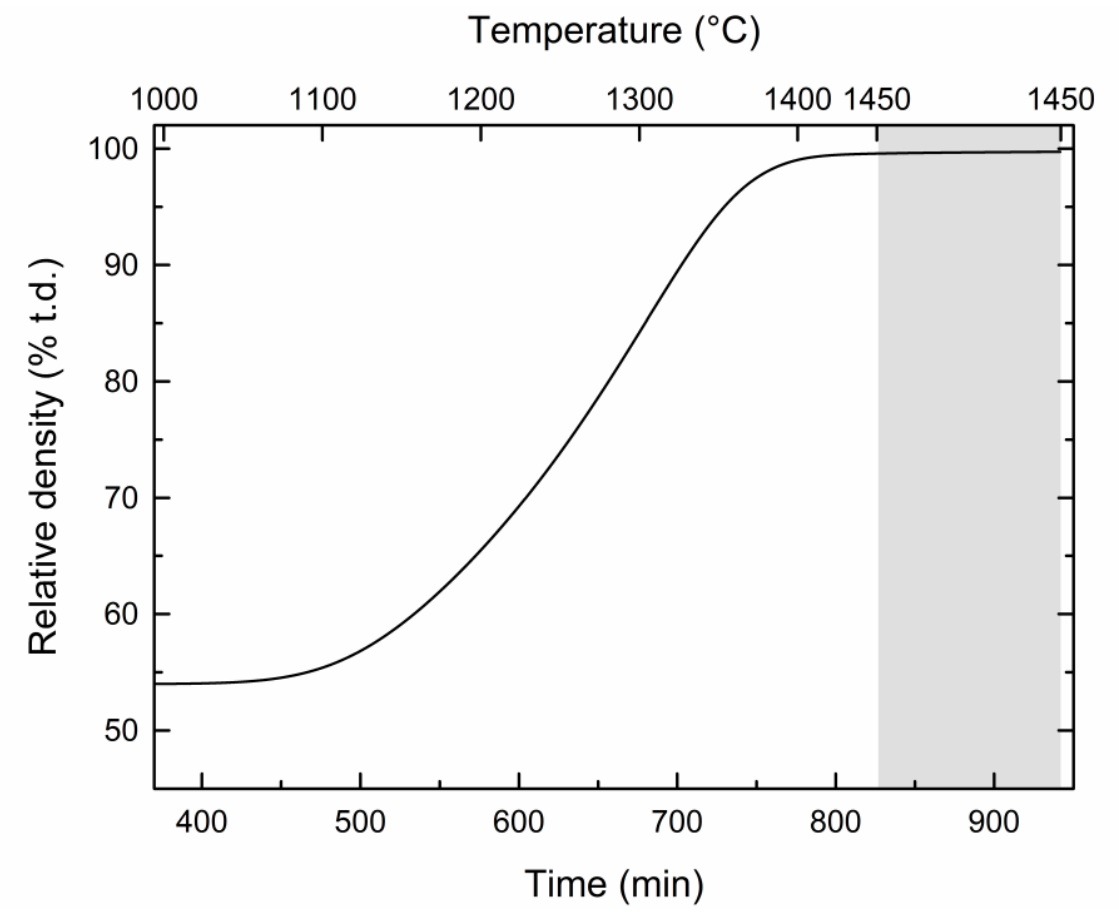

Fig. 3 Densification of zirconia samples during sintering at a heating rate of $1{ }^{\circ} \mathrm{C} \mathrm{min}^{-1}$ to the temperature of $1450{ }^{\circ} \mathrm{C}$ with a $2 \mathrm{~h}$ dwell time at the final sintering temperature. The shaded area represents dwell time at the sintering temperature.

Bodies with this pre-sintering heat treatment exhibited the best machinability, as is discussed later. The gelcast zirconia bodies densified from an initial relative density of 54\% (in the presintered state) to a relative density of $99 \%$ already at $1400{ }^{\circ} \mathrm{C}$ and reached almost full density at $1450{ }^{\circ} \mathrm{C}$, with only negligible further densification during the dwell time. The pre-sintered machinable zirconia blanks densified extremely homogeneously. Table 2 gives the linear shrinkage of samples cut from different areas of the zirconia block. The position and orientation of the measured samples in the zirconia block are shown in Fig. 4. It is shown that the shrinkage varied neither with the position nor with the direction in the block. Thus, the sintering shrinkage could be represented by just one value of $19.458 \pm 0.001 \%$, which corresponded to a scaling coefficient $k=1.242$ ( $k$ is the scaling coefficient for the CAD model to obtain correct dimensions after sintering). 
Table 2 Linear shrinkage of the machinable block (cylinder) after sintering to $1450{ }^{\circ} \mathrm{C} / 2 \mathrm{~h}$.

\begin{tabular}{lccc}
\hline Sample position & X-direction & Y-direction & Z-direction \\
& $(\%)$ & $(\%)$ & $(\%)$ \\
\hline Top & $19.44 \pm 0.04$ & $19.44 \pm 0.07$ & $19.46 \pm 0.03$ \\
Middle & $19.44 \pm 0.04$ & $19.45 \pm 0.05$ & $19.45 \pm 0.04$ \\
Bottom & $19.48 \pm 0.05$ & $19.44 \pm 0.02$ & $19.45 \pm 0.08$ \\
\hline Total & $19.46 \pm 0.02$ & $19.45 \pm 0.02$ & $19.46 \pm 0.02$
\end{tabular}

Linear shrinkage is given as average with $95 \%$ confidence interval and was measured from the optimal machinable state (pre-sintered at $1000{ }^{\circ} \mathrm{C} / 1 \mathrm{~h}$ ) to the sintered state.

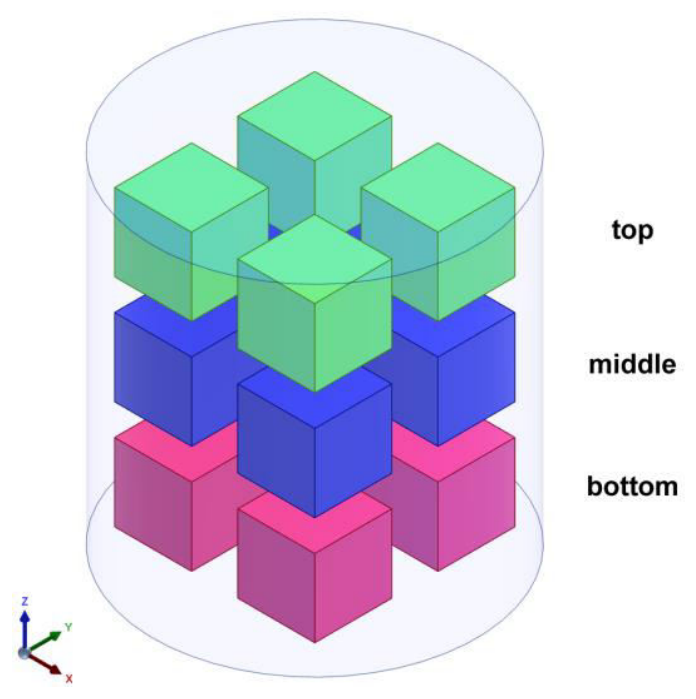

Fig. 4 Position and orientation of samples in the zirconia block (diameter of $21 \mathrm{~mm}$, height of $22 \mathrm{~mm}$ ) for the shrinkage determination.

\subsection{Structure of sintered ceramics}

The SZ samples sintered at temperatures in the range from 1350 to $1550{ }^{\circ} \mathrm{C}$ with a $2 \mathrm{~h}$ dwell time reached a relative density of $99 \%$ or more (see Table 3). Although the zirconia sample could be sintered to almost full density already at a temperature of $1350{ }^{\circ} \mathrm{C}$, sintering at higher temperatures could still remove some residual pores (99.4 vs $99.8 \%$ t.d.). 
Table 3 Density, grain size, and shrinkage of the zirconia bodies densified by different sintering temperatures.

\begin{tabular}{lcccc}
\hline Sample & $\begin{array}{c}\text { Sintering } \\
\text { temperature / dwell }\end{array}$ & Sintered & Grain & Linear \\
& density $^{\text {a }}$ & size $^{\text {a }}$ & shrinkage $^{\text {a,b }}$ \\
\hline SZ 1350 & $1350 / 2$ & $99.40 \pm 0.03$ & $230 \pm 11$ & $19.332 \pm 0.001$ \\
SZ 1450 & $1450 / 2$ & $99.80 \pm 0.03$ & $335 \pm 19$ & $19.458 \pm 0.001$ \\
SZ 1550 & $1550 / 2$ & $99.81 \pm 0.02$ & $620 \pm 25$ & $19.462 \pm 0.001$
\end{tabular}

${ }^{a}$ Sintered relative density, grain size and linear shrinkage are given as average with $95 \%$ confidence interval.

${ }^{\mathrm{b}}$ Linear shrinkage was measured from the optimal machinable state (pre-sintered at $1000{ }^{\circ} \mathrm{C} / 1 \mathrm{~h}$ ) to the sintered state.

Well dispersed mesostructured zirconia powder coupled with the gelcasting method provided an easy-to-sinter bodies, as also confirmed by the dilatometric experiments.

The microstructures of polished and thermally etched sintered samples are shown in Fig. 5. The smallest average grain size $230 \mathrm{~nm}$ was obtained after sintering at $1350{ }^{\circ} \mathrm{C}$. Increasing the sintering temperature resulted in grain growth, with the largest grain size $620 \mathrm{~nm}$ obtained after sintering at $1550{ }^{\circ} \mathrm{C}$. The histograms in Fig. 5 show the grain size distribution in sintered ceramics presented as the frequency of grain sizes (measured as intercept lengths) divided by their average values. This normalised presentation enabled a comparison of the grain size distributions irrespective of the average value of the grain size. It can be seen that the grain size distributions are similar in all samples. Thus, the main difference in the grain structures was in the average value of the grain sizes only. No inhomogeneous coarsening was observed although it is often observed in 3Y-TZP structures with a grain size close to the critical size for a spontaneous transformation [26]. The grain size, density, and shrinkage after the sintering of all samples are summarised in Table 3. 


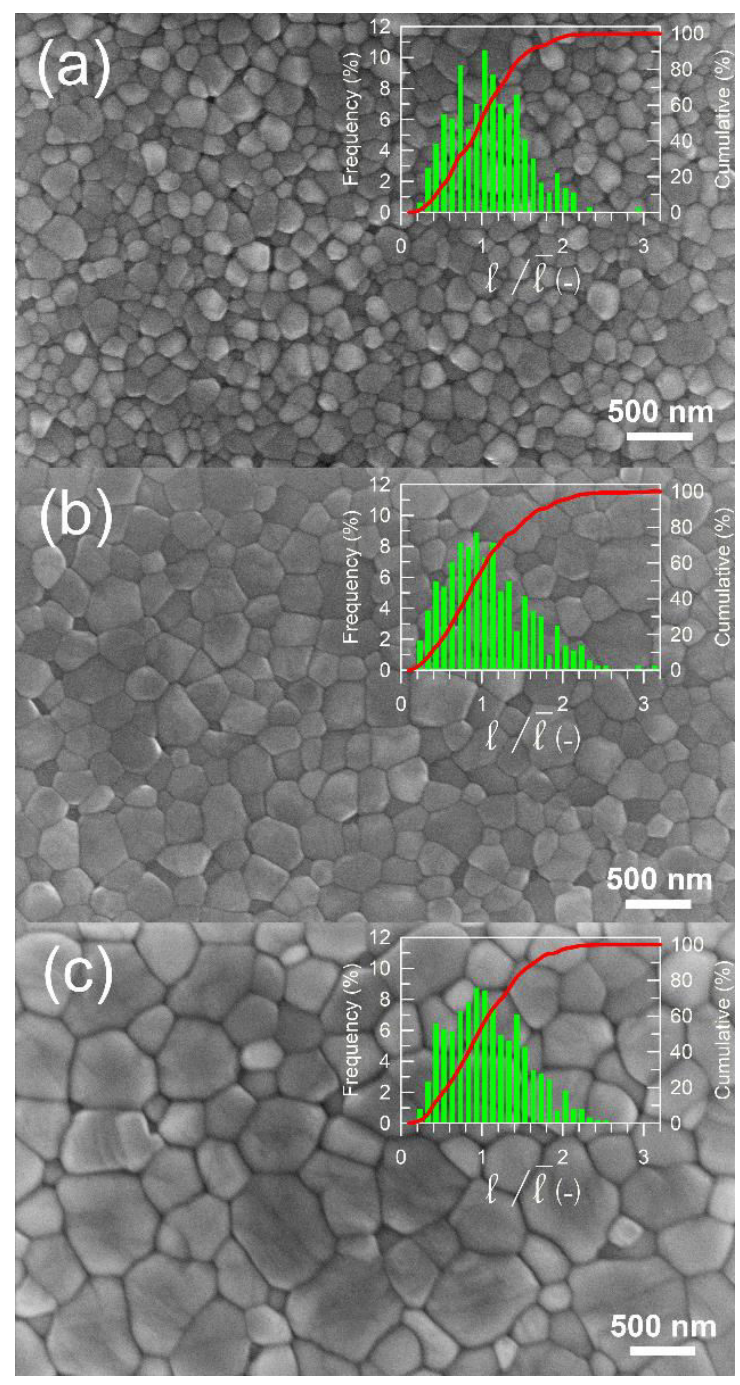

Fig. 5 SEM images showing microstructure and grain size histograms of samples sintered for two hours at temperature of (a) $1350{ }^{\circ} \mathrm{C}$, (b) $1450{ }^{\circ} \mathrm{C}$ and (c) $1550{ }^{\circ} \mathrm{C}$.

The XRD patterns of as-sintered ceramic surfaces are shown in Fig. 6 (observed data after background subtraction and $K_{\beta}$ elimination are presented). Only $\mathrm{t}-\mathrm{ZrO}_{2}$ was detected in all gelcast samples after sintering (the $\mathrm{R}_{\mathrm{wp}}$ parameters in the Rietveld analyses were $\leq 10 \%$ ). The $\mathrm{c}-\mathrm{ZrO}_{2}$ often present in $3 \mathrm{Y}-\mathrm{TZP}$ ceramics was not detected in our gelcast samples (as can be seen in Fig. 6b) and if present, its content would be negligible. It is also important to emphasize that even the sample with the average grain size of $620 \mathrm{~nm}$ (SZ 1550) had a fully tetragonal structure with no traces of $\mathrm{m}-\mathrm{ZrO}_{2}$. 


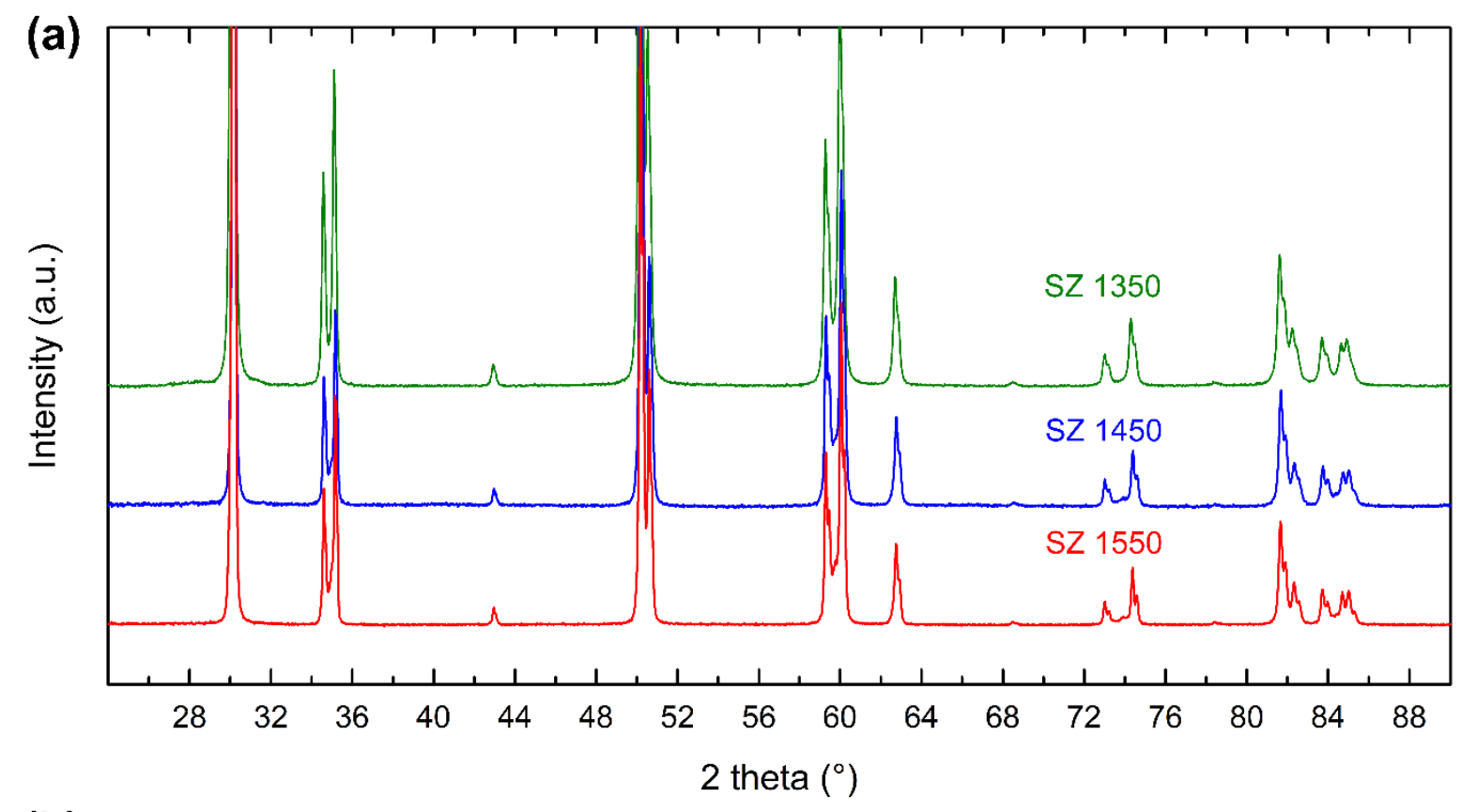

(b)
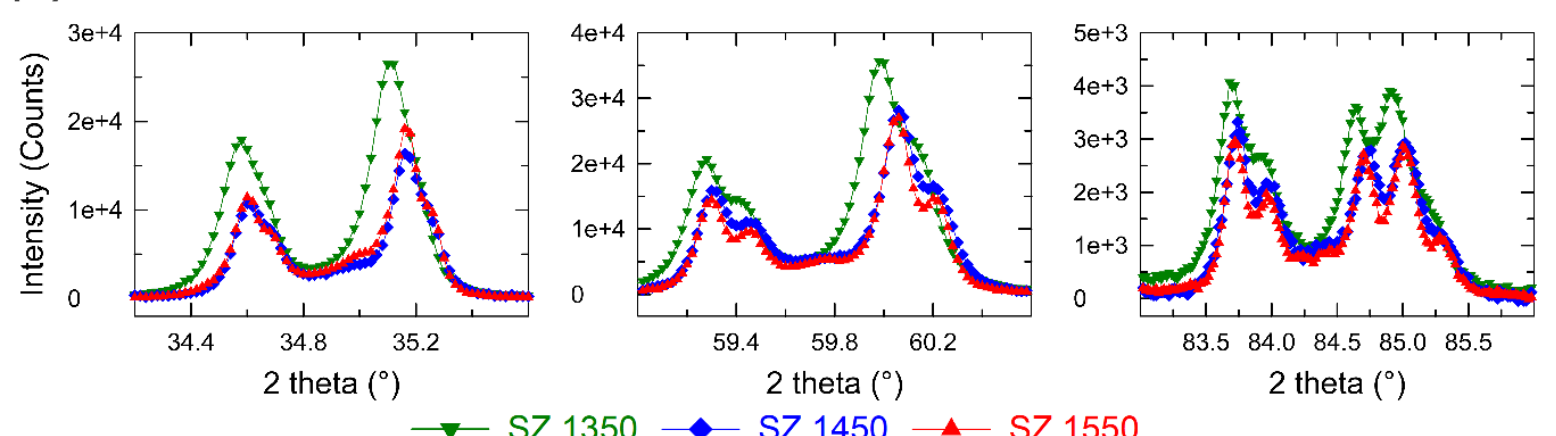

Fig. 6 XRD patterns of sintered samples: (a) full range patterns and (b) details of diffraction peaks in the $2 \theta$ ranges $34-36^{\circ}, 59-61^{\circ}$ and $83-86^{\circ}$.

\subsection{Mechanical and optical properties}

The Vickers hardness (HV5) was measured for sintered ceramics and the average values are given in Table 4. The hardness decreased with increasing grain size from HV5 $=1511$ for samples sintered at $1350{ }^{\circ} \mathrm{C}$ to $\mathrm{HV} 5=1414$ for samples sintered at $1550{ }^{\circ} \mathrm{C}$. Fig. 7 shows the hardness of individual ceramics as a function of the inverse square root of the grain size.

Because all ceramics reached a relative density of over $99 \%$, the porosity did not influence the hardness values, and the grain size and/or phase structure were the only parameters affecting 
these values. The hardness values in the graph in Fig. 7 could be reasonably fitted with a line $\left(\mathrm{R}^{2}>0.998\right)$, which means that the hardness dependence on grain size is governed by the Hall-Petch relationship [61-64]. Biaxial flexural strength was determined on the sintered ceramic discs with untreated surfaces after sintering and is summarised in Table 4 . The Weibull plots for biaxial flexural strength of zirconia ceramics developed in this study are shown in Fig. 8. The strength increased with increasing grain size. Thus, the highest average strength of $1184 \mathrm{MPa}$ was achieved in the samples sintered at $1550{ }^{\circ} \mathrm{C}$ with a grain size of $620 \mathrm{~nm}$. It is well known that fracture toughness in tetragonal zirconia ceramics increases with increasing grain size towards the critical size for the spontaneous t-m transformation [26, 65-68].

Table 4 Surface and mechanical characteristics of gelcast samples after sintering.

\begin{tabular}{|c|c|c|c|c|c|c|c|}
\hline \multirow{2}{*}{ Sample } & \multirow{2}{*}{$\begin{array}{l}\text { Hardness } \\
\text { HV5 }^{\mathrm{a}}\end{array}$} & \multicolumn{2}{|c|}{ Roughness $^{b}$} & \multirow{2}{*}{$\begin{array}{l}\text { Biaxial } \\
\text { strength }^{\mathrm{a}}\end{array}$} & \multirow{2}{*}{$\begin{array}{c}\text { Number of } \\
\text { strength samples }\end{array}$} & \multicolumn{2}{|c|}{ Weibull parameters ${ }^{a}$} \\
\hline & & $\mathrm{Ra}$ & $\mathrm{Rz}$ & & & Strength & Modulus \\
\hline & $(-)$ & $(\mu \mathrm{m})$ & $(\mu \mathrm{m})$ & $(\mathrm{MPa})$ & $(-)$ & (MPa) & $(-)$ \\
\hline SZ 1350 & $1511 \pm 16$ & $0.16 \pm 0.02$ & $1.37 \pm 0.30$ & $835 \pm 52$ & 22 & $886_{-47}^{+50}$ & $6.92_{-1.72}^{+2.34}$ \\
\hline SZ 1450 & $1472 \pm 12$ & $0.24 \pm 0.06$ & $2.45 \pm 0.75$ & $1013 \pm 43$ & 28 & $1064_{-42}^{+44}$ & $8.23_{-1.83}^{+2.39}$ \\
\hline SZ 1550 & $1414 \pm 8$ & $0.13 \pm 0.03$ & $1.16 \pm 0.23$ & $1184 \pm 47$ & 35 & $1204_{-39}^{+40}$ & $9.01_{-1.80}^{+2.27}$ \\
\hline
\end{tabular}

\footnotetext{
${ }^{a}$ Average hardness, average biaxial strength and Weibull parameters are given with $90 \%$ confidence interval. ${ }^{\mathrm{b}}$ Average roughness parameters are given with $99 \%$ confidence interval.
}

On the other hand, the maximum strength for conventional 3 Y-TZP ceramics usually reaches its maximum at a smaller grain size $[66,68,69]$ because the size of failure origins increases with microstructural coarsening $[26,70]$. However, it has been reported that zirconia nanoparticle compacts exhibit different grain growth kinetics during sintering compared with coarser (submicron) particulate compacts $[26,71]$ and could be less sensitive to this effect. 


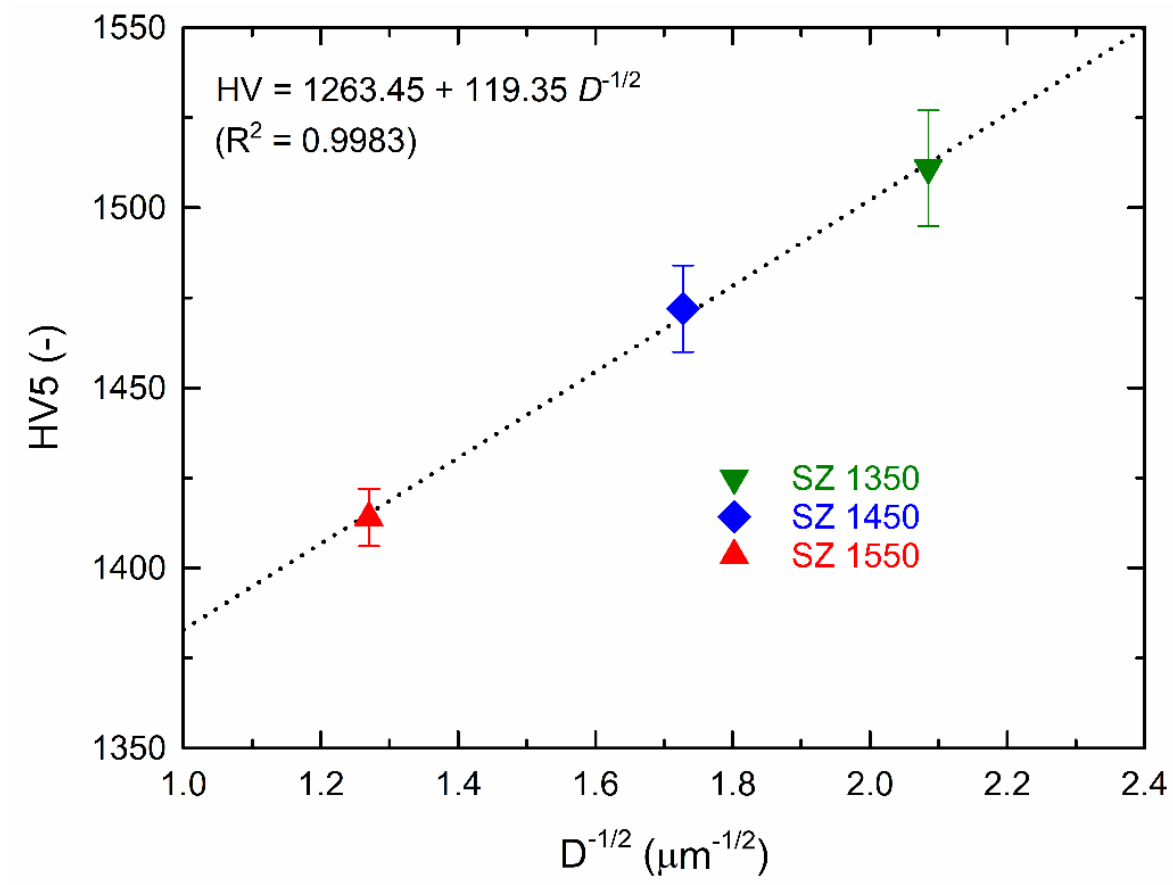

Fig. 7 Dependence of Vickers hardness of sintered ceramics on the inverse square root of grain size. Average values are given with $90 \%$ confidence interval. Coefficients of the hardness-grain size relationship are given in the graph.

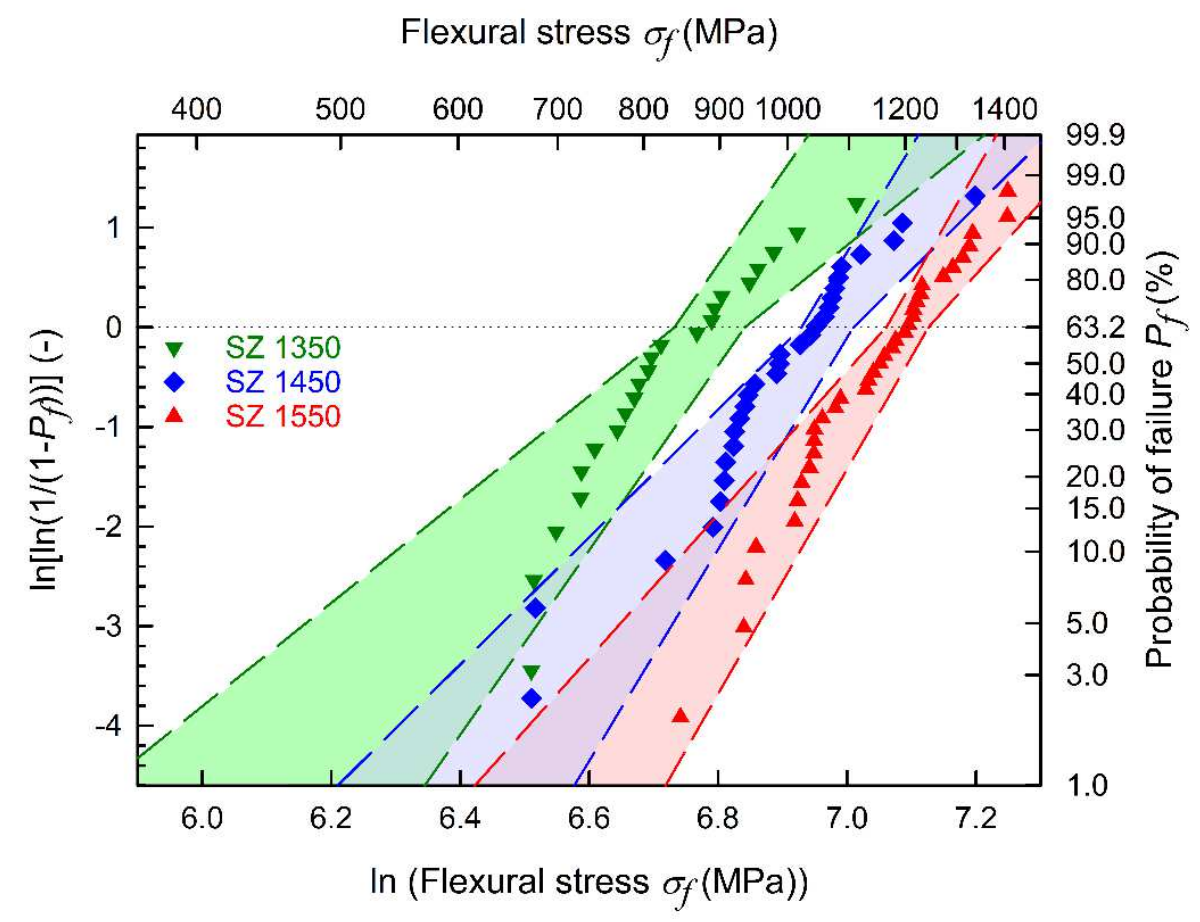


Fig. 8 Weibull plots of biaxial strength data. The dashed lines show the combined $90 \%$ confidence limit of each dataset.

This was confirmed in our investigation, where the sample based on fine mesostructured particles (75-200 nm in size) exhibited the highest strength when sintered to the coarsest structure. The Weibull modulus for the zirconia ceramics with the highest strength (sintered at $1550{ }^{\circ} \mathrm{C}$ ) was $m=9.0$. The Weibull modulus of zirconia ceramics sintered at $1350{ }^{\circ} \mathrm{C}$ was statistically lower $(m=6.9)$ than Weibull moduli of samples sintered at higher temperatures but it can be seen from the graph that some data points of SZ 1350 fell outside the confidence interval. This means that the simple two-parameter Weibull distribution does not describe the data properly and probably more defect populations were present in the SZ 1350 specimens. On the other hand, all strength data points of the ceramics sintered at $1550{ }^{\circ} \mathrm{C}$ lay within the combined confidence interval, so the Weibull distribution with the calculated parameters can be regarded as an adequate distribution for this data set. Based on the Weibull theory of effective loaded volumes [72], taking into account the more damaging loading in the biaxial testing compared to uniaxial testing and assuming the same flaw population $[50,73]$, we could estimate the 3-point and 4-point flexural strengths of the SZ 1550 ceramics from the experimental biaxial strength data. Using the effective volumes of $0.712 \mathrm{~mm}^{3}$ calculated for the discs loaded in the biaxial test (this work), $0.499 \mathrm{~mm}^{3}$ and $2.747 \mathrm{~mm}^{3}$ for rectangular test samples of nominal cross-section $2.5 \times 2 \mathrm{~mm}$ loaded in 3-point bend test, and 4-point bend test (bending test setup "A" according to the EN 843-1 standard [74]), respectively, the corresponding strengths can be recalculated according to the following equation:

$$
\frac{\sigma_{0, B T}}{\sigma_{0, B 3 B}}=\left(\frac{V_{e f f, B 3 B}}{V_{e f f, B T}}\right)^{\frac{1}{m}}
$$


where $\sigma_{0}$ is the characteristic Weibull strength, $m$ is the Weibull modulus, and $V_{\text {eff }}$ is the effective loaded volume. The subscripts $B T$ and $B 3 B$ stand for bending tests (3-point or 4point) and ball-on-3-balls tests, respectively. Using a Weibull strength of $1204 \mathrm{MPa}$ and a Weibull modulus of 9 obtained in the biaxial test, we could estimate Weibull strengths of 1252 and $1036 \mathrm{MPa}$ in 3-point and 4-point bending, respectively. The measured biaxial strength as well as the estimated 3-point and 4-point flexural strengths were at the top of currently available strengths of high-strength conventional 3Y-TZP [26, 41] and overcame the strength of dental 3Y-TZP ceramics with improved translucency and even mostly surpassed the dental low translucent high-strength zirconia (i.e. opaque dental zirconia with alumina doping) $[12,30,31,33,34,75,76]$. Moreover, it must be noted that all the strength results in this study were obtained from tests performed on samples with no surface treatment after sintering (i.e. the samples were unground and unpolished). We believe that testing a body surface prepared in a similar way as the dental restorations are prepared (i.e. by milling the pre-sintered blanks followed by sintering) better simulate the mechanical behaviour of real products.

Total forward transmittance (translucency) in the wavelength range from 300 to $800 \mathrm{~nm}$ is shown in Fig. 9 for ceramics sintered at 1450 and $1550{ }^{\circ} \mathrm{C}$. The sample sintered at $1350{ }^{\circ} \mathrm{C}$ was excluded from the transmittance experiments as a non-preferred material for dental applications due to its low strength and residual porosity. The transmittance in Fig. 9 is shown as a function of wavelength and sample thickness, where two nominal sample thicknesses, $0.5 \mathrm{~mm}$ and $1.0 \mathrm{~mm}$, were used. As expected, the transmittance was lower for thicker samples. The transmittance curves steeply rose at wavelengths between 300 and $400 \mathrm{~nm}$ and then only slowly continued to increase with increasing wavelength. The SZ 1450 and SZ 1550 samples had quite a similar transmittance in visible light and they reached transmittances of 
46.6 and $46.7 \%$ for a $0.5 \mathrm{~mm}$ thick sample, and 40.8 and $41.1 \%$ for a $1 \mathrm{~mm}$ thick sample at a wavelength of $600 \mathrm{~nm}$, respectively (see Table 5). Although many studies have described the translucency of dental materials, comparing light transmittances across different studies is difficult or even impossible for three reasons. First, different parameters are used, such as Total Forward Transmittance (TFT), Translucency Parameter (TP) or Contrast Ratio (CR). The second occasional problem is translucency misinterpretation in the case of TP or CR because these parameters describe the translucency correctly only at a transmittance of above $50 \%$ [78-80]. The third reason is the non-standardised conditions of transmittance measurement, resulting in a broad range of transmittance values. For example, one type of dental ceramic, very well known among dentists, was tested in four studies [78, 79, 81, 82], where each study used the same sample thickness and the absolute measurement of total forward transmission. The translucency varied from $26 \%$ to $62 \%$. The translucency comparison is therefore only valid within one study, where all samples are measured under the same conditions. For this reason, the translucency of the zirconia ceramics developed in our study was experimentally compared with translucency of commercial dental zirconia ceramics well established at the market. It is shown in Fig. 9 and summarized in Table 5 that commercial high-strength dental 3Y-TZP ceramics Ceramill ZI (Ceramill ZI White, Amann Girrbach, Austria), recommended for multi-unit bridges and full-arch screw retained restorations, exhibited substantially lower translucency in the whole spectrum of visible light. Even the highly translucent, low-alumina 3Y-TZP Nacera Pearl 1 (Nacera Pearl 1, Doceram Medical Ceramics, Germany) exhibited lower translucency in the whole spectrum. The benefit of the gelcasting method can be also demonstrated on the translucency of alumina-doped 3Y-TZP ceramics prepared from standard 3Y-TZP powder (TZ-3YS-E, Tosoh, Japan $)$ in previous study [41]. Even with this alumina-doped powder $(0.25 \mathrm{wt} \%$ 
$\mathrm{Al}_{2} \mathrm{O}_{3}$ ), the translucency of the sintered ceramics was close to the highly translucent Nacera Pearl 1 and well above the Ceramill ZI.

(a)

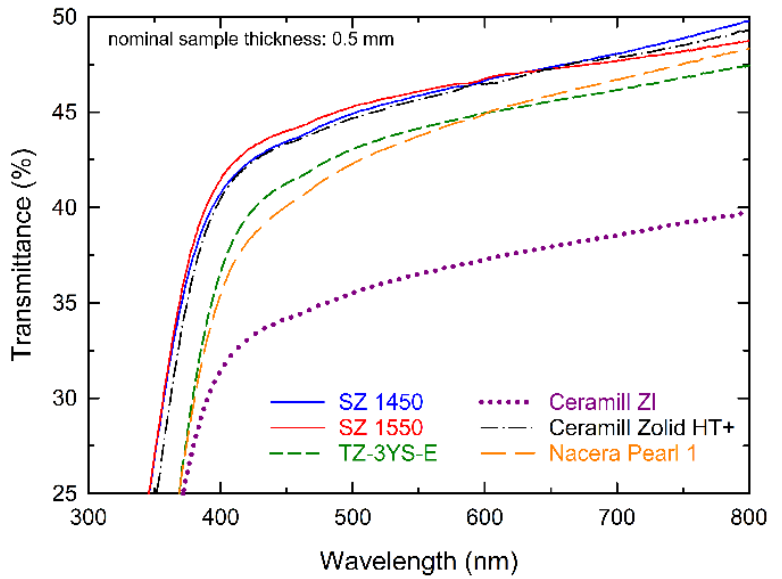

(b)

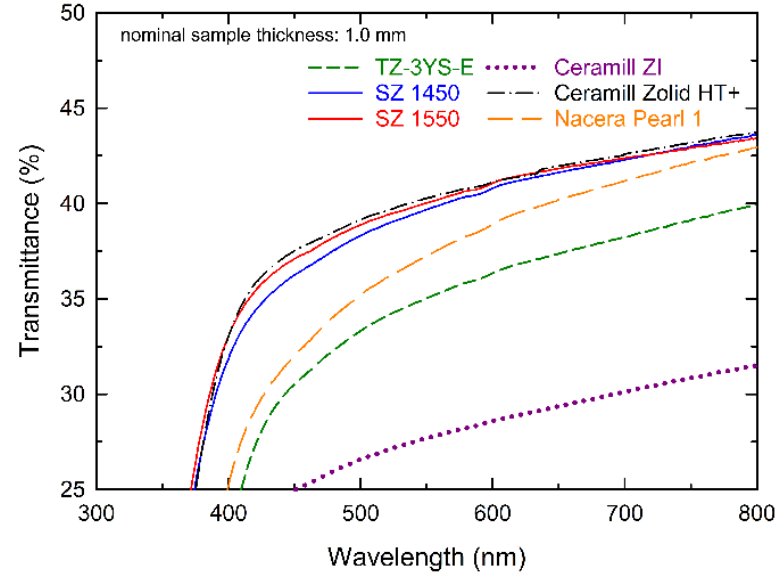

Fig. 9 Total forward transmittance as a function of wavelength for ceramic samples with nominal thicknesses: (a) $0.5 \mathrm{~mm}$ and (b) $1.0 \mathrm{~mm}$.

Table 5 Total forward transmittance (TFT) of sintered samples at a wavelength of $600 \mathrm{~nm}$.

Sintering

\begin{tabular}{|c|c|c|c|c|c|c|}
\hline \multirow[t]{2}{*}{ Sample } & \multirow[t]{2}{*}{ Producer $^{\mathrm{a}}$} & $\mathrm{Y}_{2} \mathrm{O}_{3}{ }^{\mathrm{b}}$ & $\mathrm{Al}_{2} \mathrm{O}_{3}{ }^{\mathrm{b}}$ & \multicolumn{3}{|c|}{$\begin{array}{l}\text { temperature / Thickness }{ }^{\mathrm{c}} \text { TFT }^{\mathrm{d}} \\
\text { dwell }\end{array}$} \\
\hline & & $(\mathrm{mol} \%)$ & $(\mathrm{wt} \%)$ & $\left({ }^{\circ} \mathrm{C}\right) /(\mathrm{h})$ & $(\mu \mathrm{m})$ & $(\%)$ \\
\hline SZ 1450 & this study & 3 & $<0.05$ & $1450 / 2$ & $526 \pm 2.5$ & 46.64 \\
\hline SZ 1550 & this study & 3 & $<0.05$ & $1550 / 2$ & $518 \pm 2.5$ & 46.74 \\
\hline TZ-3YS-E & [41] & 3 & 0.25 & $1450 / 2$ & $447 \pm 2.8$ & 44.97 \\
\hline Ceramill ZI & $\mathrm{AG}$ & $2.5-3.1$ & $0.25^{*}$ & $1450 / 2$ & $501 \pm 1.8$ & 37.27 \\
\hline Ceramill Zolid HT+ & $\mathrm{AG}$ & $3.8-4.1$ & $0.05 *$ & $1450 / 2$ & $500 \pm 1.2$ & 46.49 \\
\hline Nacera Pearl 1 & $\mathrm{DMC}$ & 3 & 0.002 & $1500 / 2$ & $506 \pm 2.0$ & 44.92 \\
\hline SZ 1450 & this study & 3 & $<0.05$ & $1450 / 2$ & $1011 \pm 1.4$ & 40.81 \\
\hline SZ 1550 & this study & 3 & $<0.05$ & $1550 / 2$ & $1011 \pm 2.5$ & 41.06 \\
\hline TZ-3YS-E & {$[41]$} & 3 & 0.25 & $1450 / 2$ & $1014 \pm 2.0$ & 36.36 \\
\hline Ceramill ZI & $\mathrm{AG}$ & $2.5-3.1$ & $0.25^{*}$ & $1450 / 2$ & $1000 \pm 1.0$ & 28.60 \\
\hline Ceramill Zolid HT+ & $\mathrm{AG}$ & $3.8-4.1$ & $0.05 *$ & $1450 / 2$ & $1004 \pm 1.8$ & 41.14 \\
\hline Nacera Pearl 1 & DCM & 3 & 0.002 & $1500 / 2$ & $1003 \pm 1.6$ & 38.91 \\
\hline
\end{tabular}

${ }^{\mathrm{a}}$ The producer abbreviation stands for Amann Girrbach (AG) and Doceram Medical Ceramics (DMC) 
${ }^{\mathrm{b}}$ Yttria and alumina contents are presented according to the data of the powder/blank producer or based on Ref. [77] (marked with asterisk).

${ }^{\mathrm{c}}$ Average thickness is given with the $95 \%$ confidence interval.

$\mathrm{d} 95 \%$ confidence interval for transmittance was below $0.05 \%$.

Nevertheless, our approach applying the gelcasting method and the fine mesostructured powder with a low-alumina content enhanced the translucency even more. The visible light transmittance of gelcast SZ 1450 or SZ 1550 samples was comparable to the transmittance of commercial 4Y-TZP dental ceramics Ceramill Zolid HT+ (Ceramill Zolid HT+ White, Amann Girbach, Austria) marked by producer as highly translucent zirconia. Ceramill Zolid HT+ contained a mixed cubic/tetragonal structure with $38 \%$ of cubic phase (Fig. S1 and Table $\mathrm{S} 1$ in the Supplementary material). However, it is well documented that increasing the content of $\mathrm{c}-\mathrm{ZrO}_{2}$ in the zirconia structure inevitably results in a strength and reliability reduction [13, 34]. We have shown that eliminating alumina and other dopants, decreasing the residual porosity after sintering, and utilising a homogeneous coarse-grained structure (i.e. decreasing the number of backscattering centres) in $3 \mathrm{Y}$-TZP ceramics leads to improved translucency without forfeiting excellent mechanical properties. The ceramics based on fine mesostructured $3 \mathrm{Y}-\mathrm{ZrO}_{2}$ particles and processed by the gelcasting method provided a favourable combination of high translucency comparable with a common cubic/tetragonal 4Y-TZP, and very high strength available only in the pure tetragonal $3 \mathrm{Y}-\mathrm{TZP}$.

The machinable zirconia discs and blocks were pre-sintered to a temperature of $1000{ }^{\circ} \mathrm{C}$ with a dwell time of $1 \mathrm{~h}$. This heat treatment exhibited the most suitable combination of milling conditions and surface roughness. The surface roughness of sintered discs is given in Table 4 . A representative surface map of sintered sample is shown in Fig. 10. 


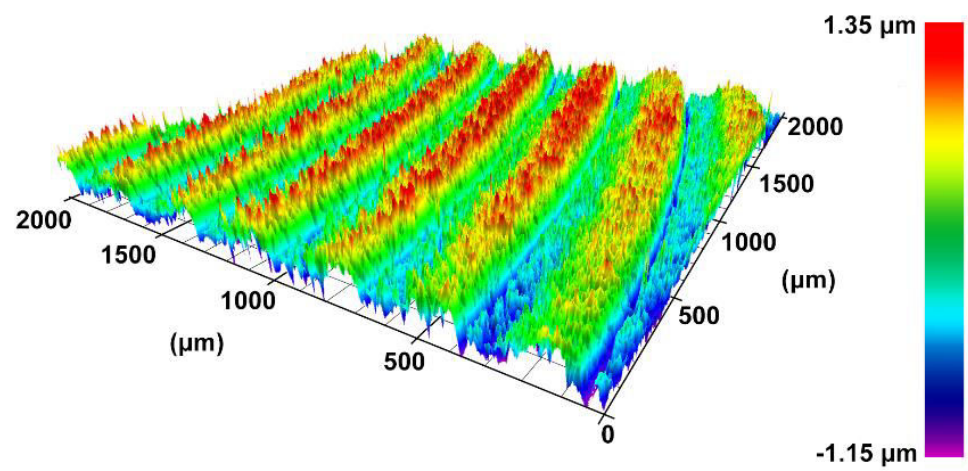

Fig. 10 Surface topography after milling and sintering of the sample sintered at $1550{ }^{\circ} \mathrm{C}$ used for biaxial strength testing.

Typical milling traces were observed on the sample surface. It is interesting to note that this smooth milling surface $\left(\mathrm{Ra}=0.13 \mu \mathrm{m}\right.$ after sintering at $1550{ }^{\circ} \mathrm{C}$ ) could be achieved with a relatively dense machinable ceramic $\left(54.0 \%\right.$ t.d. after the pre-sintering at $\left.1000{ }^{\circ} \mathrm{C} / 1 \mathrm{~h}\right)$. The gel-cast bodies were densely packed and started to densify at this optimum pre-sintering temperature, but the mesostructured particles could be still easily removed during milling, providing a smooth surface. Using the presented processing method, blanks of typical dimensions used in dentistry (cylindrical block, large disc) could be prepared (Fig. 11). Fig. 12 shows the individual steps of $3 \mathrm{Y}$-TZP crown production from the pre-sintered cylindrical block with a very smooth surface after milling and a glossy appearance after sintering. 


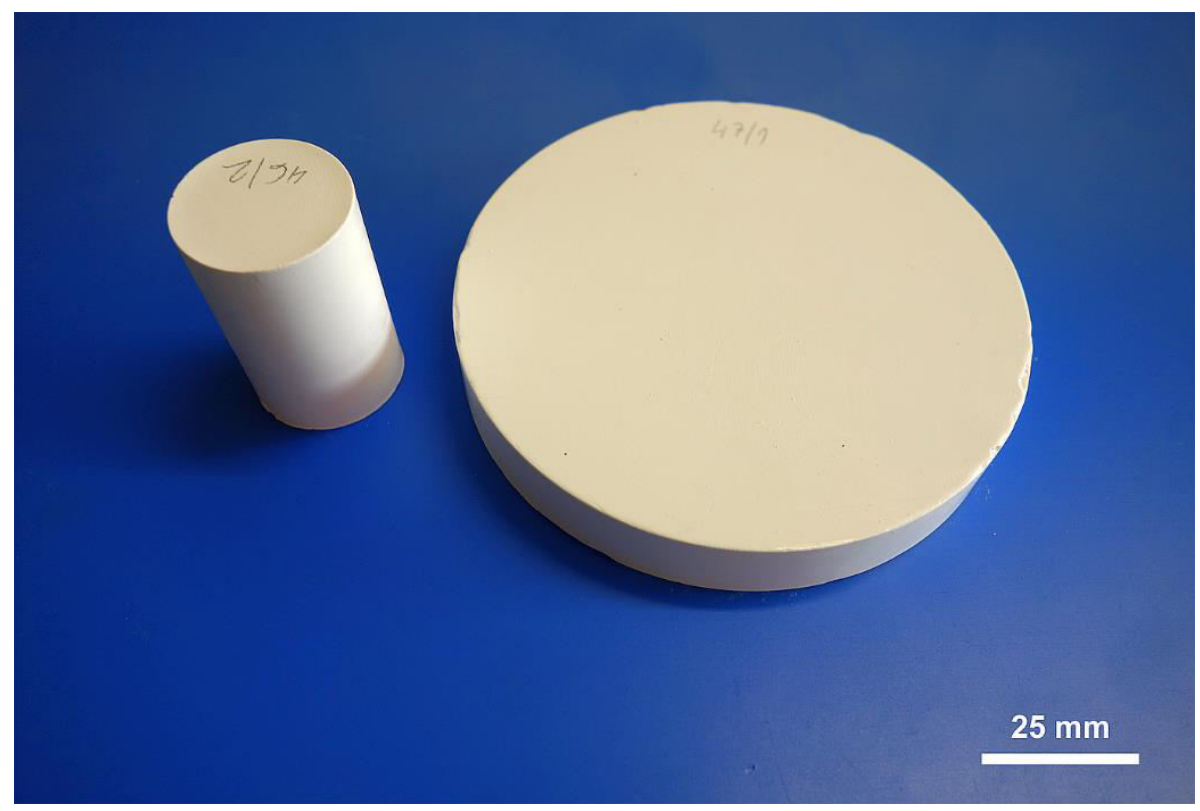

Fig. 11 Pre-sintered dental blanks in the shape of a cylinder (diameter of $24 \mathrm{~mm}$ and height of $39 \mathrm{~mm}$ ) and disc (diameter of $92 \mathrm{~mm}$ and thickness of $14 \mathrm{~mm}$ ).

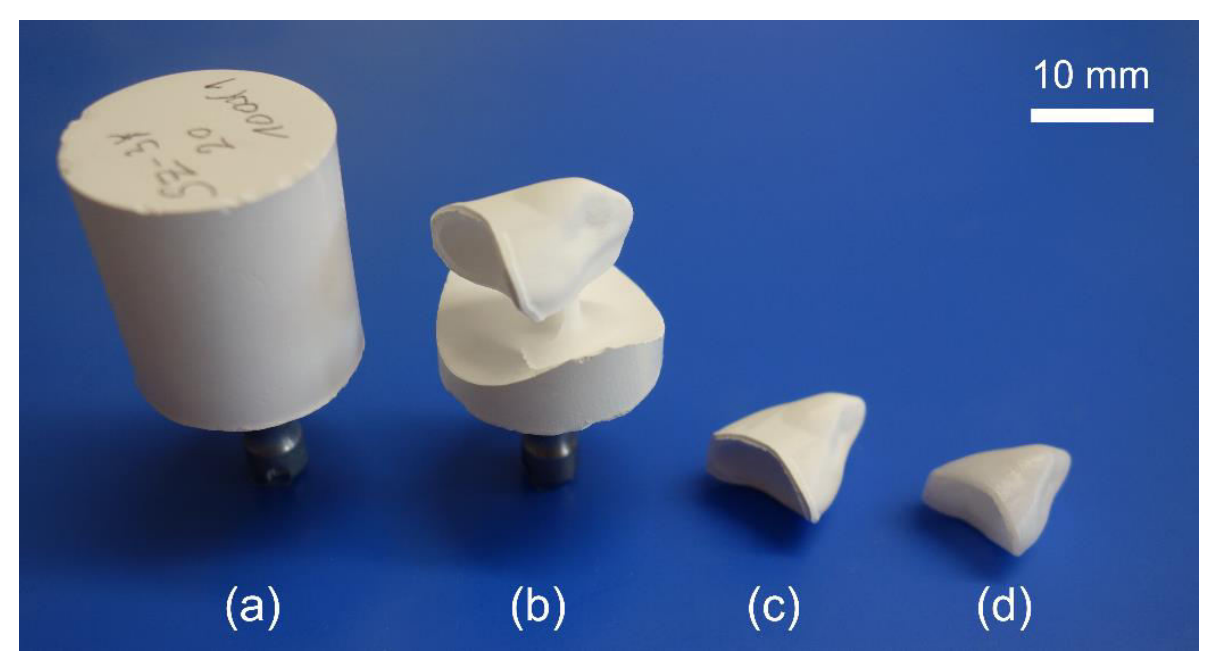

Fig. 12 Individual stages of dental 3Y-TZP crown production showing (a) pre-sintered SZ block prepared in this study, (b) crown after milling connected to a stub, (c) crown before sintering and (d) crown after sintering at $1550{ }^{\circ} \mathrm{C}$ for $2 \mathrm{~h}$. (This crown was prepared using Zfx Inhouse5x milling machine with a $1 \mathrm{~mm}$ diamond-coated ball-end milling tool.) 


\section{Conclusions}

Dental zirconia ceramics of excellent strength and, simultaneously, enhanced translucency have been developed. The processing method was based on the gelcasting of mesostructured zirconia particles stabilised with $3 \mathrm{~mol} \%$ of $\mathrm{Y}_{2} \mathrm{O}_{3}$. The method provided defect-free zirconia machinable blanks of high green density, which could be easily sintered to a density of over $99.8 \%$ of theoretical density with fully tetragonal phase structure. The highest biaxial strength $1184 \mathrm{MPa}$ was obtained in the ceramic with an average grain size of $620 \mathrm{~nm}$. A translucency of $46.7 \%$ at a wavelength of $600 \mathrm{~nm}$ was determined for a $0.5 \mathrm{~mm}$ thick sample. The newly developed dental 3 Y-TZP ceramic offers isotropic shrinkage, strength at the top level and reasonably high translucency, suitable for demanding multi-unit restorations.

\section{Acknowledgement}

This article is dedicated to the memory of the late Professor James Zhijian Shen, who encouraged us to realize this work. Presented research was financially supported by the Czech Science Foundation under the grant 20-20175S and by the Ministry of Education, Youth and Sports of the Czech Republic under the grant LTACH19034. Part of the work was carried out with the support of CEITEC Nano Research Infrastructure (MEYS CR, 2016-2019). L.S. would like to gratefully acknowledge the financial support by the National Key R\&D Program of China (Grant No. 2018YFE0109100) by Ministry of Science and Technology, China. The authors wish to thank the company Dens Technika, Brno, Czech Republic for help with dental milling experiments.

Electronic Supplemetary Material: Supplementary material with XRD analyses of gelcast and commercial dental ceramics is available in the on-line version of this article at https://doi.org/10.1007/s40145-... 


\section{References}

[1] Andersson M, Odén A. A new all-ceramic crown: A dense-sintered, high-purity alumina coping with porcelain. Acta Odontol Scand 1993, 51: 59-64.

https://doi.org/10.3109/00016359309041149

[2] Andersson M, Razzoog ME, Odén A, Hegenbarth EA, Lang BR. Procera: a new way to achieve an all-ceramic crown. Quintessence Int 1998, 29: 285-296.

[3] Chen Y-M, Smales RJ, Yip KHK, Sung W-J. Translucency and biaxial flexural strength of four ceramic core materials. Dent Mater 2008, 24: 1506-1511.

https://doi.org/10.1016/j.dental.2008.03.010

[4] Baldissara P, Llukacej A, Ciocca L, Valandro FL, Scotti R. Translucency of zirconia copings made with different CAD/CAM systems. J Prosthet Dent 2010, 104: 6-12. https://doi.org/10.1016/S0022-3913(10)60086-8

[5] Swain MV. Unstable cracking (chipping) of veneering porcelain on all-ceramic dental crowns and fixed partial dentures. Acta Biomater 2009, 5: 1668-1677.

https://doi.org/10.1016/j.actbio.2008.12.016

[6] Chai H, Lee JJW, Mieleszko AJ, Chu SJ, Zhang Y. On the interfacial fracture of porcelain/zirconia and graded zirconia dental structures. Acta Biomater 2014, 10: 3756-3761. https://doi.org/10.1016/j.actbio.2014.04.016

[7] Kelly JR, Tesk JA, Sorensen JA. Failure of All-ceramic Fixed Partial Dentures in vitro and in vivo: Analysis and Modeling. J Dent Res 1995, 74: 1253-1258.

https://doi.org/10.1177/00220345950740060301

[8] White SN, Miklus VG, McLaren EA, Lang LA, Caputo AA. Flexural strength of a layered zirconia and porcelain dental all-ceramic system. J Prosthet Dent 2005, 94: 125-131. https://doi.org/10.1016/j.prosdent.2005.05.007 
[9] Beuer F, Stimmelmayr M, Gueth J-F, Edelhoff D, Naumann M. In vitro performance of full-contour zirconia single crowns. Dent Mater 2012, 28: 449-456.

https://doi.org/10.1016/j.dental.2011.11.024

[10] Marchack BW, Sato S, Marchack CB, White SN. Complete and partial contour zirconia designs for crowns and fixed dental prostheses: A clinical report. J Prosthet Dent 2011, 106: 145-152. https://doi.org/10.1016/S0022-3913(11)60112-1

[11] Sulaiman TA, Abdulmajeed AA, Donovan TE, Ritter AV, Vallittu PK, Närhi TO, Lassila LP. Optical properties and light irradiance of monolithic zirconia at variable thicknesses. Dent Mater 2015, 31: 1180-1187. https://doi.org/10.1016/j.dental.2015.06.016

[12] Matsuzaki F, Sekine H, Honma S, Takanashi T, Furuya K, Yajima Y, Yoshinari M. Translucency and flexural strength of monolithic translucent zirconia and porcelain-layered zirconia. Dent Mater J 2015, 34: 910-917. https://doi.org/10.4012/dmj.2015-107

[13] Zhang Y, Lawn BR. Novel Zirconia Materials in Dentistry. J Dent Res 2017, 97: 140147. https://doi.org/10.1177/0022034517737483

[14] Apetz R, van Bruggen MPB. Transparent Alumina: A Light-Scattering Model. J Am Ceram Soc 2003, 86: 480-486. https://doi.org/10.1111/j.1151-2916.2003.tb03325.x

[15] Krell A, Klimke J, Hutzler T. Transparent compact ceramics: Inherent physical issues. Opt Mater 2009, 31: 1144-1150. https://doi.org/10.1016/j.optmat.2008.12.009

[16] Klimke J, Trunec M, Krell A. Transparent Tetragonal Yttria-Stabilized Zirconia Ceramics: Influence of Scattering Caused by Birefringence. J Am Ceram Soc 2011, 94: 18501858. https://doi.org/10.1111/j.1551-2916.2010.04322.x

[17] Shahmiri R, Standard OC, Hart JN, Sorrell CC. Optical properties of zirconia ceramics for esthetic dental restorations: A systematic review. J Prosthet Dent 2018, 119: 36-46. https://doi.org/10.1016/j.prosdent.2017.07.009 
[18] Ghodsi S, Jafarian Z. A Review on Translucent Zirconia. Eur J Prosthodont Restor Dent 2018, 26: 62-74, https://doi.org/10.1922/EJPRD_01759Ghodsi13.

[19] Manziuc M-M, Gasparik C, Negucioiu M, Constantiniuc M, Burde A, Vlas I, Dudea D. Optical properties of translucent zirconia: A review of the literature. Eurobiotech J 2019, 3:45-51. https://doi.org/10.2478/ebtj-2019-0005

[20] Zhang H, Li Z, Kim B-N, Morita K, Yoshida H, Hiraga K, Sakka Y. Effect of Alumina Dopant on Transparency of Tetragonal Zirconia. J Nanomater 2012, 2012: 269064, https://doi.org/10.1155/2012/269064.

[21] Verkerk MJ, Winnubst AJA, Burggraaf AJ. Effect of impurities on sintering and conductivity of yttria-stabilized zirconia. J Mater Sci 1982 17: 3113-3122. https://doi.org/10.1007/BF01203473

[22] Matsui K, Yamakawa T, Uehara M, Enomoto N, Hojo J. Mechanism of AluminaEnhanced Sintering of Fine Zirconia Powder: Influence of Alumina Concentration on the Initial Stage Sintering. J Am Ceram Soc 2008, 91: 1888-1897. https://doi.org/10.1111/j.1551$\underline{2916.2008 .02350 . x}$

[23] Al-Kaisy N, Garib BT. Selecting maxillary anterior tooth width by measuring certain facial dimensions in the Kurdish population. J Prosthet Dent 2016, 115: 329-334. https://doi.org/10.1016/j.prosdent.2015.08.012

[24] Trunec M, Klimke J, Shen ZJ. Transparent alumina ceramics densified by a combinational approach of spark plasma sintering and hot isostatic pressing. J Eur Ceram Soc 2016, 36: 4333-4337. https://doi.org/10.1016/j.jeurceramsoc.2016.06.004

[25] Zhang Y. Making yttria-stabilized tetragonal zirconia translucent. Dent Mater 2014, 30: 1195-1203. https://doi.org/10.1016/j.dental.2014.08.375

[26] Trunec M. Effect of grain size on mechanical properties of 3Y-TZP ceramics. CeramSilikaty 2008, 52: 165-171. 
[27] Eichler J, Rödel J, Eisele U, Hoffman M. Effect of Grain Size on Mechanical Properties of Submicrometer 3Y-TZP: Fracture Strength and Hydrothermal Degradation. J Am Ceram Soc 2007, 90: 2830-2836. https://doi.org/10.1111/j.1551-2916.2007.01643.x

[28] Suresh A, Mayo MJ, Porter WD, Rawn CJ. Crystallite and Grain-Size-Dependent Phase Transformations in Yttria-Doped Zirconia. J Am Ceram Soc 2003, 86: 360-362. https://doi.org/10.1111/j.1151-2916.2003.tb00025.x [29] Lange FF. Transformation-Toughened $\mathrm{ZrO}_{2}$ : Correlations between Grain Size Control and Composition in the System $\mathrm{ZrO}_{2}-\mathrm{Y}_{2} \mathrm{O}_{3}$. J Am Ceram Soc 1986, 69: 240-242. https://doi.org/10.1111/j.1151-2916.1986.tb07416.x [30] Zhang F, Inokoshi M, Batuk M, Hadermann J, Naert I, Van Meerbeek B, Vleugels J. Strength, toughness and aging stability of highly-translucent Y-TZP ceramics for dental restorations. Dent Mater 2016, 32: e327-e337. https://doi.org/10.1016/j.dental.2016.09.025 [31] Camposilvan E, Leone R, Gremillard L, Sorrentino R, Zarone F, Ferrari M, Chevalier J. Aging resistance, mechanical properties and translucency of different yttria-stabilized zirconia ceramics for monolithic dental crown applications. Dent Mater 2018, 34: 879-890. https://doi.org/10.1016/j.dental.2018.03.006 [32] Zhang F, Reveron H, Spies BC, Van Meerbeek B, Chevalier J. Trade-off between fracture resistance and translucency of zirconia and lithium-disilicate glass ceramics for monolithic restorations. Acta Biomater 2019, 91: 24-34.

https://doi.org/10.1016/j.actbio.2019.04.043

[33] Harada A, Shishido S, Barkarmo S, Inagaki R, Kanno T, Örtengren U, Egusa H, Nakamura K. Mechanical and microstructural properties of ultra-translucent dental zirconia ceramic stabilized with 5 mol\% yttria. J Mech Behav Biomed Mater 2020, 111: 103974. https://doi.org/10.1016/j.jmbbm.2020.103974 
[34] Jerman E, Lümkemann N, Eichberger M, Zoller C, Nothelfer S, Kienle A, Stawarcyzk B. Evaluation of translucency, Marten's hardness, biaxial flexural strength and fracture toughness of 3Y-TZP, 4Y-TZP and 5Y-TZP materials. Dent Mater 2021, 37: 212-222. https://doi.org/10.1016/j.dental.2020.11.007

[35] Stawarczyk B, Keul C, Eichberger M, Figge D, Edelhoff D, Lümkemann N. Three generations of zirconia: From veneered to monolithic. Part II. Quintessence Int 2017, 48: 441450. https://doi.org/10.3290/j.qi.a38157

[36] Michailova M, Elsayed A, Fabel G, Edelhoff D, Zylla I-M, Stawarczyk B. Comparison between novel strength-gradient and color-gradient multilayered zirconia using conventional and high-speed sintering. J Mech Behav Biomed Mater 2020, 111: 103977.

https://doi.org/10.1016/j.jmbbm.2020.103977

[37] Kaizer MR, Kolakarnprasert N, Rodrigues C, Chai H, Zhang Y. Probing the interfacial strength of novel multi-layer zirconias. Dent Mater 2020, 36: 60-67.

https://doi.org/10.1016/j.dental.2019.10.008

[38] Grech J, Antunes E. Zirconia in dental prosthetics: A literature review. J Mater Res

Technol 2019, 8: 4956-4964. https://doi.org/10.1016/j.jmrt.2019.06.043

[39] Sigmund WM, Bell NS, Bergström L. Novel Powder-Processing Methods for Advanced Ceramics. J Am Ceram Soc 2000, 83: 1557-1574. https://doi.org/10.1111/j.11512916.2000.tb01432.x

[40] Lewis JA. Colloidal Processing of Ceramics. J Am Ceram Soc 2000, 83: 2341-2359. https://doi.org/10.1111/j.1151-2916.2000.tb01560.x

[41] Kastyl J, Chlup Z, Stastny P, Trunec M. Machinability and properties of zirconia ceramics prepared by gelcasting method. Adv Appl Ceram 2020, 119: 252-260. https://doi.org/10.1080/17436753.2019.1675402 
[42] Bera O, Trunec M. Optimization of Fine Alumina Gelcasting Using In Situ Dynamic Rheology. J Am Ceram Soc 2012, 95: 2849-2856. https://doi.org/10.1111/j.15512916.2012.05293.x

[43] Trunec M, Kastyl J, Stastny P, Hidebrandt S. Processing of large and complex-shaped fine-grained alumina bodies with high transparency. J Eur Ceram Soc 2021, 41: 2016-2022. https://doi.org/10.1016/j.jeurceramsoc.2020.10.065

[44] EN 623-2:1993 Advanced technical ceramics - Monolithic ceramics - General and textural properties - Part 2: Determination of density and porosity. Bruxelles: CEN, 1993. [45] Piconi C, Porporati AA. Bioinert Ceramics: Zirconia and Alumina. In Handbook of Bioceramics and Biocomposites. Antoniac IV, Ed. Cham: Springer International Publishing, 2016: 59-89. https://doi.org/10.1007/978-3-319-12460-5_4

[46] Maca K, Pouchly V, Drdlik D, Hadraba H, Chlup Z. Dilatometric study of anisotropic sintering of alumina/zirconia laminates with controlled fracture behaviour. J Eur Ceram Soc 2017, 37: 4287-4295. https://doi.org/10.1016/j.jeurceramsoc.2017.04.030

[47] Kastyl J, Pouchly V, Trunec M. Co-extrusion of zirconia core-shell rods with controlled porosity in the core. Process Appl Ceram 2017, 37: 4287-4295.

https://doi.org/10.2298/PAC1803230K

[48] ASTM E1382-97:2015 Standard Test Methods for Determining Average Grain Size Using Semiautomatic and Automatic Image Analysis. West Conshohocken: ASTM Int, 2015. https://doi.org/10.1520/E1382-97R15

[49] MENDELSON MI. Average Grain Size in Polycrystalline Ceramics. J Am Ceram Soc 1969, 52: 443-446. https://doi.org/10.1111/j.1151-2916.1969.tb11975.x

[50] Börger A, Supancic P, Danzer R. The ball on three balls test for strength testing of brittle discs: stress distribution in the disc. J Eur Ceram Soc 2002, 22: 1425-1436.

https://doi.org/10.1016/S0955-2219(01)00458-7 
[51] EN 843-5:2007 Advanced technical ceramics - Mechanical properties of monolithic ceramics at room temperature - Part 5: Statistical analysis. Bruxelles: CEN, 1993.

[52] ASTM E1348-15e1:2015, Standard Test Method for Transmittance and Color by Spectrophotometry Using Hemispherical Geometry. West Conshohocken: ASTM Int, 2015. https://doi.org/10.1520/E1348-15E01

[53] EN ISO 4287:1997, Geometrical Product Specifications (GPS) - Surface texture: Profile method - Terms, definitions and surface texture parameters, Geneva: International Organisation for Standardization, 1998.

[54] EN ISO 4288:1998, Geometric Product Specifications (GPS) - Surface texture: Profile method - Rules and procedures for the assessment of surface texture, Geneva: International Organisation for Standardization, 1998.

[55] Gwyddion software (GNU GPL license), version 2.49. Information on http://gwyddion.net/.

[56] Liu L, Eriksson M, Zou J, Zhong Y, Liu Q, Liu Z, Chiu Y-L, Shen Z. Self-supported yttria-stabilized zirconia mesocrystals with tunable mesopores prepared by a chemi-thermal process. J Materiomics 2019, 5: 350-356. https://doi.org/10.1016/j.jmat.2019.03.001 [57] Trunec M, Maca K. Compaction and Pressureless Sintering of Zirconia Nanoparticles. J Am Ceram Soc 2007, 90: 2735-2740. https://doi.org/10.1111/j.1551-2916.2007.01781.x

[58] Trunec M, Pouchly V. Colloidal processing of low-concentrated zirconia nanosuspension using osmotic consolidation. Ceram Int 2016, 42: 11838-11843.

https://doi.org/10.1016/j.ceramint.2016.04.105

[59] Trunec M, Misak J. Consolidation of nanoparticle suspensions by centrifugation in nonporous moulds. Ceram Int 2014, 40: 7775-7782.

https://doi.org/10.1016/j.ceramint.2013.12.120 
[60] Krell A, Klimke J. Effects of the Homogeneity of Particle Coordination on Solid-State Sintering of Transparent Alumina. J Am Ceram Soc 2006, 89: 1985-1992. https://doi.org/10.1111/j.1551-2916.2006.00985.x

[61] Ratzker B, Wagner A, Sokol M, Meshi L, Kalabukhov S, Frage N. Deformation in nanocrystalline ceramics: A microstructural study of $\mathrm{MgAl}_{2} \mathrm{O}_{4}$. Acta Mater 2020, 183: 137144. https://doi.org/10.1016/j.actamat.2019.11.015

[62] Akatsu T, Numata S, Yoshida M, Shinoda Y, Wakai F. Indentation Size Effect on the Hardness of Zirconia Polycrystals. In Fracture Mechanics of Ceramics. Bradt RC, Munz D, Sakai M, White KW, Eds. Boston: Springer US, 2005, 13-20.

[63] Feng L, Bokov A, Dillon SJ, Castro RHR. Size-induced room temperature softening of nanocrystalline yttria stabilized zirconia. J Eur Ceram Soc 2020, 40: 2050-2055.

https://doi.org/10.1016/j.jeurceramsoc.2020.01.046

[64] Novitskaya E, Karandikar K, Cummings K, Mecartney M, Graeve OA. Hall-Petch effect in binary and ternary alumina / zirconia / spinel composites. J Mater Res Technol 2021, 11: 823-832. https://doi.org/10.1016/j.jmrt.2021.01.058

[65] Lange FF. Transformation toughening - Part 3 Experimental observations in the $\mathrm{ZrO}_{2}$ $\mathrm{Y}_{2} \mathrm{O}_{3}$ system. J Mater Sci 1982, 17: 240-246. https://doi.org/10.1007/BF00809059

[66] Ruiz L, Readey MJ. Effect of Heat Treatment on Grain Size, Phase Assemblage, and Mechanical Properties of 3 mol\% Y-TZP. J Am Cer Soc 1996, 79: 2331-2340.

https://doi.org/10.1111/j.1151-2916.1996.tb08980.x

[67] Bravo-Leon A, Morikawa Y, Kawahara M, Mayo MJ. Fracture toughness of nanocrystalline tetragonal zirconia with low yttria content. Acta Mater 2002, 50: 4555-4562. https://doi.org/10.1016/S1359-6454(02)00283-5 
[68] Casellas D, Feder A, Llanes L, Anglada M. Fracture toughness and mechanical strength of Y-TZP/PSZ ceramics. Scripta Mater 2001, 45: 213-220. https://doi.org/10.1016/S1359$\underline{6462(01) 01020-X}$

[69] Swain MV, Rose LRF. Strength Limitations of Transformation-Toughened Zirconia Alloys. J Am Ceram Soc 1986, 69: 511-518. https://doi.org/10.1111/j.1151-

2916.1986.tb04785.x

[70] Casellas D, Alcalá J, Llanes L, Anglada M. Fracture variability and R-curve behavior in yttria-stabilized zirconia ceramics. J Mat Sci 2001, 36: 3011-3025.

https://doi.org/10.1023/A:1017923008382

[71] Trunec M, Chlup Z. Higher fracture toughness of tetragonal zirconia ceramics through nanocrystalline structure. Scripta Mater 2009, 61: 56-59.

https://doi.org/10.1016/j.scriptamat.2009.03.019

[72] Wachtman JB, Cannon WR, Matthewson MJ. Mechanical properties of ceramics. New York: John Wiley \& Sons, 2009.

[73] Danzer R, Harrer W, Supancic P, Lube T, Wang Z, Börger A. The ball on three balls test—Strength and failure analysis of different materials. J Eur Ceram Soc 2007, 27: 14811485. https://doi.org/10.1016/j.jeurceramsoc.2006.05.034

[74] EN 843-1:2008 Advanced technical ceramics - Mechanical properties of monolithic ceramics at room temperature - Part 1: Determination of flexural strength. Bruxelles: CEN, 2008.

[75] Tanaka H, Maeda T, Narikiyo H, Morimoto T. Mechanical properties of partially stabilized zirconia for dental applications. J Asian Ceram Soc 2019, 7: 460-468. https://doi.org/10.1080/21870764.2019.1665767 
[76] Borges MAP, Alves MR, dos Santos HES, dos Anjos MJ, Elias CN. Oral degradation of Y-TZP ceramics. Ceram Int 2019, 45: 9955-9961.

https://doi.org/10.1016/j.ceramint.2019.02.038

[77] Jansen JU, Lümkemann N, Letz I, Pfefferle R, Sener B, Stawarczyk B. Impact of highspeed sintering on translucency, phase content, grain sizes, and flexural strength of 3Y-TZP and 4Y-TZP zirconia materials. J Prosthet Dent 2019, 122: 396-403.

https://doi.org/10.1016/j.prosdent.2019.02.005

[78] Spink LS, Rungruanganut P, Megremis S, Kelly JR. Comparison of an absolute and surrogate measure of relative translucency in dental ceramics. Dent Mater, 2013, 29: 702-707. https://doi.org/10.1016/j.dental.2013.03.021

[79] Nogueira AD, Della Bona A. The effect of a coupling medium on color and translucency of CAD-CAM ceramics. J Dent 2013, 41: e18-e23.

https://doi.org/10.1016/j.jdent.2013.02.005

[80] Ali AAB, Kang K, Finkelman M, Zandparsa R, Hirayama H. The effect of variations in translucency and background on color differences in CAD/CAM lithium disilicate glass ceramics. J Prosthodont 2014, 23: 213-220. https://doi.org/10.1111/jopr.12080 [81] Awad D, Stawarczyk B, Liebermann A, Ilie N. Translucency of esthetic dental restorative $\mathrm{CAD} / \mathrm{CAM}$ materials and composite resins with respect to thickness and surface roughness. J Prosthet Dent 2015, 113: 534-540.

https://doi.org/10.1016/j.prosdent.2014.12.003

[82] Nassary Zadeh P, Lümkemann N, Sener B, Eichberger M, Stawarczyk B. Flexural strength, fracture toughness, and translucency of cubic/tetragonal zirconia materials. $J$ Prosthet Dent 2018, 120: 948-954. https://doi.org/10.1016/j.prosdent.2017.12.021 


\section{Table captions}

Table 1 Composition of the zirconia suspension.

Table 2 Linear shrinkage of the machinable block (cylinder) after sintering to $1450{ }^{\circ} \mathrm{C} / 2 \mathrm{~h}$.

Table 3 Density, grain size, and shrinkage of the zirconia bodies densified by different sintering temperatures.

Table 4 Surface and mechanical characteristics of gel-cast samples after sintering.

Table 5 Total forward transmittance (TFT) of sintered samples at a wavelength of $600 \mathrm{~nm}$.

\section{Figure captions}

Fig. 1 Morphology of SZ-3Y zirconia powder shown in a) SEM and b) TEM imaging mode.

Fig. 2 Particle size distribution in zirconia suspensions after ball milling and pore size distribution in zirconia bodies pre-sintered to $800{ }^{\circ} \mathrm{C} / 0 \mathrm{~h}, 1000{ }^{\circ} \mathrm{C} / 1 \mathrm{~h}$, and $1100{ }^{\circ} \mathrm{C} / 1 \mathrm{~h}$.

Fig. 3 Densification of zirconia samples during sintering at a heating rate of $1{ }^{\circ} \mathrm{C} \mathrm{min}^{-1}$ to the temperature of $1450{ }^{\circ} \mathrm{C}$ with a $2 \mathrm{~h}$ dwell time at the final sintering temperature. The shaded area represents dwell time at the sintering temperature.

Fig. 4 Position and orientation of samples in the zirconia block (diameter of $21 \mathrm{~mm}$, height of $22 \mathrm{~mm}$ ) for the shrinkage determination.

Fig. 5 SEM images showing microstructure and grain size histograms of samples sintered for two hours at temperature of (a) $1350{ }^{\circ} \mathrm{C}$, (b) $1450{ }^{\circ} \mathrm{C}$ and (c) $1550{ }^{\circ} \mathrm{C}$.

Fig. 6 XRD patterns of sintered samples: (a) full range patterns and (b) details of diffraction peaks in the $2 \theta$ ranges $34-36^{\circ}, 59-61^{\circ}$ and $83-86^{\circ}$.

Fig. 7 Dependence of Vickers hardness of sintered ceramics on the inverse square root of grain size. Average values are given with $90 \%$ confidence interval. Coefficients of the hardness-grain size relationship are given in the graph. 
Fig. 8 Weibull plots of biaxial strength data. The dashed lines show the combined $90 \%$ confidence limit of each dataset.

Fig. 9 Total forward transmittance as a function of wavelength for ceramic samples with nominal thicknesses: (a) $0.5 \mathrm{~mm}$ and (b) $1.0 \mathrm{~mm}$.

Fig. 10 Surface topography after milling and sintering of the sample sintered at $1550{ }^{\circ} \mathrm{C}$ used for biaxial strength testing.

Fig. 11 Pre-sintered dental blanks in the shape of a cylinder (diameter of $24 \mathrm{~mm}$ and height of $39 \mathrm{~mm}$ ) and disc (diameter of $92 \mathrm{~mm}$ and thickness of $14 \mathrm{~mm}$ ).

Fig. 12 Individual stages of dental 3Y-TZP crown production showing (a) pre-sintered SZ block prepared in this study, (b) crown after milling connected to a stub, (c) crown before sintering and (d) crown after sintering at $1550{ }^{\circ} \mathrm{C}$ for $2 \mathrm{~h}$. (This crown was prepared using Zfx Inhouse 5x milling machine with a $1 \mathrm{~mm}$ diamond-coated ball-end milling tool.) 


\section{Supplementary Files}

This is a list of supplementary files associated with this preprint. Click to download.

- Electronicsupplementarymaterial.docx 